Document downloaded from:

http://hdl.handle.net/10251/52702

This paper must be cited as:

Delgado Galván, XV.; Izquierdo Sebastián, J.; Benítez López, J.; Pérez García, R. (2014). Joint stakeholder decision-making on the management of the Silao-Romita aquifer using AHP. Environmental Modelling \& Software. 51:310-322. doi:10.1016/j.envsoft.2013.10.008.

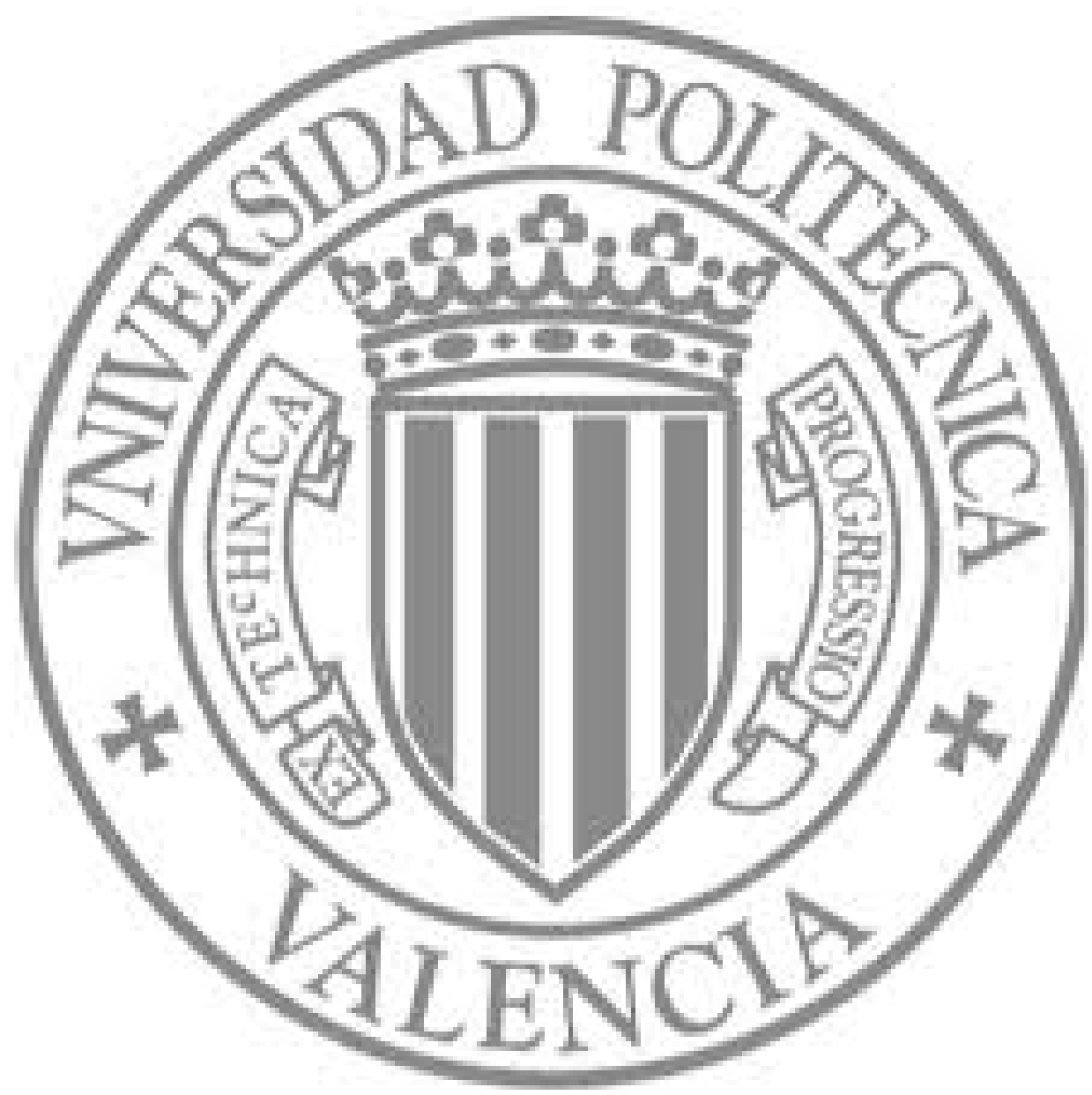

The final publication is available at

http://dx.doi.org/10.1016/j.envsoft.2013.10.008

Copyright Elsevier 


\title{
Joint Stakeholder Decision-Making on the Management of the Silao-Romita Aquifer Using AHP
}

\author{
Delgado-Galván, X. ${ }^{\mathrm{a}}$, Izquierdo, J. ${ }^{\mathrm{b} 1}$, Benítez, J. ${ }^{\mathrm{c}}$, Pérez-García, R. ${ }^{\mathrm{b}}$ \\ ${ }^{a}$ Ingeniería Geomática e Hidráulica, Universidad de Guanajuato, Juárez 77, 36000, Guanajuato, Mexico \\ ${ }^{\mathrm{b}}$ FluIng-IMM, Universitat Politècnica de València, Camino de Vera, s/n, 46022, Valencia, Spain \\ ${ }^{\mathrm{c}}$ IMM, Universitat Politècnica de València, Camino de Vera, s/n, 46022, Valencia, Spain
}

\begin{abstract}
Over-exploitation and pollution have been identified as the main problems facing the Silao-Romita aquifer in Guanajuato, Mexico. The objective of this paper is to analyze the current situation, characterized by a clear lack of legislative enforcement, dispersion of competences, and scarcity of economic resources, in order to establish a new prioritization of action plans, and choose from among three specific management options. One of the main challenges when addressing these problems in a holistic manner is the conflicting viewpoints of the sectors involved. As each stakeholder has a different perception, there is a clear need for appropriate mechanisms to reach a consensus in decision-making. To achieve the objective, we use the Analytic Hierarchy Process (AHP), because of its flexibility and the availability of mathematical axiomatic principles and techniques to obtain group preferences and priorities. In addition, we use several tools developed by the authors to obtain consistency, streamline the trade-off between stakeholder know-how and synthetic consistency, and consistently complete partial judgments given by some of the stakeholders. The problem of obtaining a consensus among the actors involved regarding criteria and alternatives is also considered. The obtained results are intended to serve as guidelines for conducting priority actions to help solve the general problem of the study area, and to identify the management model that best meets the needs of the aquifer, according to the actors involved.
\end{abstract}

Keywords: aquifer management, decision-making, participatory modeling, analytic hierarchy process

\section{Introduction}

The National Water Program 2007-2012 (CNA, 2008) considers as its fifth objective the participation of users and society, suitably organized, in water management. To this end, it is considered essential to foster a new culture based on a shared sense of hydric community and responsibility. Within this objective, the participation of federations, regional states, and municipalities, as well as society as a whole, is considered essential. Watershed councils are examples where users and authorities jointly engage in decision-making. Mexico currently has 26 watershed councils dating from 1993 (CNA, 2011). Several watershed council subsidiary bodies handle specific problems: sub-basins commisions, micro-basins committees, groundwater technical committees for aquifers, and clean beach committees in coastal areas. However, there are no clear rules for decision making in each of these organs.

To encourage the generation of feasible solutions to efficiently manage available water resources, the National Water Commission of Mexico (CONAGUA), through the State Water Commission of Guanajuato (CEAG) promotes the creation of groundwater user groups, termed COTAS for

\footnotetext{
${ }^{1}$ Corresponding author. Tel.: +34628028804 .

Email addresses: xdelgado@ugto.mx (X. Delgado-Galván), jizquier@upv.es (J. Izquierdo),

jbenitez@mat.upv.es (J. Benítez), rperez@upv.es (R. Pérez-García).
} 
Consejos Técnicos de Aguas Subterráneas (groundwater technical councils). The Silao-Romita aquifer COTAS council was created in 1999 with the mission of encouraging and advising on the efficient use of water. Since this council was created a number of steps have been taken to solve the general problems of the aquifer and these steps have partially solved some specific (minor) problems. Nevertheless, there is broad agreement that the general problem of the study area is overexploitation and pollution, resulting in the emergence of several specific (major) problems. There is a need for action aimed at solving the main problems of the aquifer by ensuring the participation of all the sectors involved.

The work performed before this study had provided the various stakeholders with specific expertise, obviously conditioned by each stakeholder's interests and points of view. One of the pillars of the integrated water resource management (IWRM) paradigm is public participation. However, such participation never impacted on the area - despite the fact that stakeholders' interests and points of view exhibited clear conflicts that could prevent communication. Currently, it is generally agreed that better decisions are implemented with less conflict and more success when they are driven by stakeholders (Voinov and Bousquet, 2010). Moreover, IWRM is a reference framework for the current water management in many countries (Letcher and Giupponi, 2004). For example, the Water Framework Directive (WFD, European Commission, Directive/2000/60/EC) was enforced in Europe in 2000.

The current trend toward greater interactive involvement of citizens in policy making is unavoidable and highly desirable. Participation is good in itself. Environmental projects and programs are likely to be more relevant, successful, and sustainable if their actors are involved in planning, implementation, and evaluation (Younge and Fowkes, 2003; Richards et al., 2004; Stringer et al., 2007; Lippe et al., 2011; Oliver et al., 2012). Public participation is also likely to improve the quality of decisions; using a wider pool of knowledge and understanding can avoid obstacles that would obstruct effective implementation of a particular decision (Fischer, 2000; Beierle, 2002; Reed et al., 2006). Public participation is, however, not a panacea. Collaboration and participation cannot solve every problem, and should not be used as a surrogate for other systematic attempts to plan and manage environmental issues (Oliver, 2002; Demeritt et al., 2009). Public participation efforts must be responsive to the needs of the stakeholders. It is critical to recognize that participation processes require a flexible approach that is appropriate to needs (Burton et al., 2004; Bojórquez-Tapia et al., 2004; Vedwan et al., 2008). Participatory processes may seem very risky, but there is growing evidence that, if well designed, these perceived risks may be well worth taking (Reed, 2008).

The differing viewpoints of the sectors involved present a major challenge when addressing a real participatory decision-making process. As each stakeholder has a different perception, there is a clear need for appropriate mechanisms to achieve consensus (Mysiak et al., 2005). Such instruments must be conceived as decision support systems (DSS) and tools that, steered by disciplinary experts, may facilitate participation and the direct involvement of stakeholders in a way that is coherent - even though for some purposes just implicitly - with the so-called 'hard science' modeling approaches (Sgobbi and Giupponi, 2007; Giupponi et al., 2008).

In this work we start by analyzing the current situation of the Silao-Romita aquifer to first establish a new prioritization of action plans and decide which of three specific management options is best suited for current aquifer conditions. Overall, the process follows most of the steps defined in wellknown procedural approaches of participatory modeling found in the literature (Castelletti and Soncini-Sessa, 2006; Soncini-Sessa et al., 2007; Giupponi, 2007; Ceccato et al., 2010). The starting point is the expertise and perception of the various stakeholders regarding the current problems faced by users and the environment. It is clear that none of the actors has a comprehensive knowledge of the problem. However, it should be noted that all the aspects are eventually considered if none of the sectors involved is excluded. For example, even though most of the quantitative (science-based) considerations that can be made from engineering, economic, and operational points of view are not explicitly considered, the expertise of some of the actors includes them implicitly. However, urban and agricultural water users endow the process with the practical, human, and social points of view clearly required in a participatory process. 
The phases involved, including stakeholder selection, objective setting, identification of criteria, selection of alternatives, and collection of data, are described in the paper. For the analysis phase, multi-criteria analysis (MCA) provides a framework for decision analysis: consisting of steps and procedures for a piecewise conceptualization of the problem involving multiple objectives and criteria, and a set of techniques aiming at elicitation, introspection, and aggregation of decision preferences (Figueira et al., 2005). A large number of MCA methods exist to rank, compare and/or select the most suitable policy options according to the chosen criteria (Greco et al., 2005). Among the currently MCA methodologies (including AHP, TOPSIS, PROMETHEE and ELECTRE), we have selected the Analytic Hierarchy Process (AHP) (Saaty, 1977). We focus on AHP's strengths and flaws in the discussion section.

AHP has proven to be an adequate method for reflecting decision-maker judgments in complex decision making processes (Awasthi and Chauhan, 2011; Bottero et al., 2011; Gao and Hailu, 2012). It may also be helpful during the process of analyzing problems, not only with groundwater in the case of the COTAS, but in the management of other water sources. The present work illustrates an option to achieve consensus in the decision-making process implied by the National Water Program consultation period 2013-2018. This consultation period requires the participation of the various actors involved in water management in the Silao-Romita aquifer.

In AHP, stakeholder judgment is compiled into so-called comparison matrices and then the priorities of the elements are calculated. In this study, the selected stakeholders included aquifer users, researchers, technicians, and managers - and they were consulted (as explained later) in specific work sessions conducted by one of the authors (XDG).

This work is an extension of (Delgado-Galván et al., 2012a) where a partial application of AHP enabled a prioritization plan based on the opinion of just one expert and a single comparison of criteria (possible action plans). In this work, the prioritization of action plans is further studied by considering the judgment of six stakeholders who are representative of the sectors involved. Three management options are proposed, and the aim is to use a process of aggregation of priorities to decide which is the most suitable management option for tackling the problems of the aquifer. In addition, the problem of obtaining a consensus among the actors involved is considered in this paper (both with respect to criteria and alternatives) by using four aggregation methods. Consensus is understood in the context of this work as the way we build a group preference from individual preferences using the so-called aggregation of individual preference technique. We have specifically considered the possibility of using individual weights in the aggregations, weights that have been obtained following specific AHP work with the various stakeholders involved. Finally, we have used various tools developed by the authors to obtain consistency, streamline the trade-off between specific know-how and synthetic consistency, and consistently complete the partial judgments given by some of the stakeholders. As a result, we have attempted to implement an environmental decision support system where the interaction of humans and the ecosystem plays a key role, and which can cope with a highly complex environmental and multidisciplinary problem (Sánchez-Marrè et al., 2008; Kelly et al., 2013; Delden et al., 2011).

The paper is organized as follows. In Section 2 we briefly describe AHP and the tools used to perform the study. In Section 3 we give the details of the case-study. We then present the specific application in Section 4, and provide the obtained results and discussion in Section 5. Finally, we present the conclusions and future lines of study in Section 6.

\section{Methods: AHP and some related tools}

The analytic hierarchy process (AHP) was developed by Thomas L. Saaty (1977) and is intended to formalize the intuitive understanding of complex problems. The purpose of the method is to enable the decision maker to structure a multi-criteria problem by building a hierarchical model that has three levels: goal or objective; criteria; and alternatives. Once the hierarchical model is constructed, pairwise comparisons between these elements (criteria and alternatives) are compiled into square matrices, whose coefficients are numerical values assigned to the preferences indicated by the experts consulted. The process ends by providing a synthesis that aggregates these opinions. 
The foundation of the process is giving numerical values to judgments made by people, which helps measure how much each element of the hierarchy affects the next level. For these comparisons, use is sometimes made of the nine-point scale developed by Saaty $(1980,2001)$. However, there are other scales of values (Dong et al., 2008). It should be noted that the scale can be extended to the use of intermediate values if it is considered that a judgment is between two possible values in the scale. Comparisons between pairs are quantified by using the selected scale. The scale lists a number of verbal opinions and a discrete set of numbers that represent the importance or weight of verbal opinions. In the case of the nine-point Saaty scale, integer values from 1 to 9 are used to describe comparisons of importance between two elements, ranging from 'equal importance' when using 1, and progressively increasing the importance with higher values until reaching 'much greater importance' with 9.

In the first step the expert makes comparisons between pairs of elements. A square matrix, $A_{n \times n}$, is built when performing pairwise comparisons between the elements involved - and matrix entry $(i, j)$ is a number representing the comparison between elements $i$ and $j$, according to the scale used; and $n$ is the number of elements compared. All the considerations for the construction of comparison matrices apply equally to the comparison of criteria and to the comparison of alternatives for each criterion. To extract priority vectors from the comparison matrices we use the eigenvector method, which was first proposed by Saaty in his seminal paper (Saaty, 1977).

\subsection{Properties of comparison matrices}

A comparison matrix, $A$, exhibits three basic properties, namely positivity $\left(a_{i j}>0\right.$, for all $\left.i, j\right)$; homogeneity $\left(a_{i j}=1\right.$, if elements $i$ and $j$ are considered equally important: in particular $a_{i i}=1$ for every $i)$; and reciprocity $\left(a_{j i}=1 / a_{i j}\right.$ for all $\left.i, j\right)$. Besides these properties, a third property consistency - should theoretically be desirable for a comparison matrix. A positive $n \times n$ matrix is consistent if $a_{i k}=a_{i j} a_{j k}$, for all $i, j, k$. Consistency expresses the coherence that may exist among judgments about the elements of a set. Since preferences are expressed in a subjective manner it is reasonable (and, arguably, even desirable) for some kind of incoherence to exist. When dealing with intangibles, judgments are rarely consistent unless they are forced in some artificial manner.

Among the various characterizations of consistent matrices, we recall the one given in (Benitez et al., 2011a): an $n \times n$ positive matrix $A$ is consistent if and only if there is a vector $x$ in $R^{n}$ such that $A$ $=x J(x)^{\mathrm{T}}$, where $J$ is the map associating a positive matrix $X=\left(x_{i j}\right)$ with the matrix whose entry $(i, j)$ is $1 / x_{i j}$ (remember that if $X$ is any matrix, $X^{\mathrm{T}}$ denotes the transpose matrix of $X$ ). This characterization is used to build the consistent matrix that is closest to a given comparison matrix, once a suitable prioritization vector has been obtained. This prioritization vector is closely related with the so-called Perron vector of a positive matrix. The principal eigenvalue of a comparison matrix and its associated eigenvector (Perron vector) provides information for complex decisionmaking: the normalized Perron eigenvector provides the priority vector sought (Saaty 2003, 2008a).

Generally, however, $A$ is not consistent. The hypothesis that the estimates of these values are small perturbations of the 'correct' values also guarantees a small perturbation of the eigenvalues (see for example, (Stewart, 2001)). For non-consistent matrices, the problem to be solved is the eigenvalue problem $A w=\lambda_{\max } w$, where $\lambda_{\max }$ is the single largest eigenvalue of $A$, which provides the Perron eigenvector as an estimate of the vector of priorities. As a measure of the inconsistency, Saaty proposes using the consistency index $C I=\left(\lambda_{\max }-n\right) /(n-1)$ and the consistency ratio $C R=C I / R I$, where $R I$ is Saaty's average consistency index (Saaty, 2001). If $C R<0.1$, the estimate is accepted, otherwise, a new comparison matrix is requested until $C R<0.1$.

\subsection{The linearization process}

Several alternatives have been proposed in the literature to help improve consistency. In this paper we use a method based on a linearization technique (Benítez et al., 2011a) together with an 
iterative feedback process to achieve an acceptable level of consistency while complying to some degree with expert preferences.

The process starts with a comparison matrix provided by the expert(s). Most comparison matrices are non-consistent. Moreover, with non-negligible probability most comparison matrices do not have acceptable consistency ratios. Various prioritizing processes, in particular, the proposed linearization technique, can then be used to build a consistent matrix. However, with non-negligible probability, the new matrix thus generated may be considered by the expert(s) to only partially reflect their opinions, and they may choose to modify some of the matrix entries. Shifting one or more entries of the matrix - while preserving reciprocity - will produce a new non-consistent matrix and a similar process can again be undergone in an attempt to reach a reasonable trade-off between consistency and expert know-how compliance.

We offer here a concise enunciation of the linearization process. This process (Benítez et al., 2011a) states that the closest consistent matrix to an $n \times n$ positive reciprocal matrix $A$ can be obtained through the orthogonal projection onto $\mathcal{L}_{n}=\{L(A): A n \times n$ positive consistent matrix $\}$, a subspace of dimension $n-1$ of the space of $n \times n$ matrices, $L(A)$, where $L$ associates a positive matrix $X=\left(x_{i j}\right)$ with the matrix whose $(i, j)$ element is $\log \left(x_{i j}\right)$. This orthogonal projection is given by a suitable Fourier expansion

$$
p_{n}(L(A))=\frac{1}{2 n} \sum_{i=1}^{n-1} \frac{\operatorname{trace}\left(L(A)^{T} \phi_{n}\left(y_{i}\right)\right)}{\left\|y_{i}\right\|_{2}^{2}} \phi_{n}\left(y_{i}\right),
$$

where $\phi_{n}$ is defined by $\phi_{n}(v)=v 1_{n}^{\mathrm{T}}-1_{n} v^{\mathrm{T}}, v \in R^{n}$, with $1_{n}$ being the vector $(1 \ldots 1)^{\mathrm{T}}$ in $R^{n}$, and the set $\left\{y_{1}, \ldots, y_{n-1}\right\}$ is an orthogonal basis of the orthogonal complement of the linear span of $1_{n}$.

In (Benítez et al., 2013a) the authors have shown that, for reciprocal matrices, this projection can be obtained with great simplicity by using the formula,

$$
p_{n}(L(A))=\frac{1}{n}\left[\left(L(A) U_{n}\right)-\left(L(A) U_{n}\right)^{T}\right],
$$

where $U_{n}=1_{n} 1_{n}^{\mathrm{T}}$.

Since this formula involves only sums, computational efficiency is guaranteed and integration in any AHP-based DSS is straightforward and of great interest.

Finally, the closest consistent matrix to $A$ is given by $A^{c}=E\left(p_{n}(L(A))\right)$, where $E$ associates a matrix $X=\left(x_{i j}\right)$ with the matrix whose $(i, j)$ entry is $\exp \left(x_{i j}\right)$.

The entire linearization process is described by (2),

$$
A \stackrel{L}{\longrightarrow} L(A) \stackrel{p_{n}}{\longrightarrow} p_{n}(L(A)) \stackrel{E}{\longrightarrow} A^{c},
$$

a simple matrix process which uses the maps $L$ and $E$ and the projection defined by (1). As an example, for the following (left-most) inconsistent matrix (incidentally, corresponding to the first alternative matrix for actor \#1- see Section 4.2) the process is

$$
\left(\begin{array}{ccc}
1 & 3 & 3 \\
0.33 & 1 & 3 \\
0.33 & 0.33 & 1
\end{array}\right) \stackrel{L \rightarrow p_{n}}{\longrightarrow}\left(\begin{array}{ccc}
0 & 0.73 & 1.47 \\
-0.73 & 0 & 0.73 \\
-1.47 & -0.73 & 0
\end{array}\right) \stackrel{E}{\longrightarrow}\left(\begin{array}{ccc}
1 & 2.08 & 4.33 \\
0.48 & 1 & 2.08 \\
0.23 & 0.48 & 1
\end{array}\right),
$$

and the result is a consistent (right-most) matrix.

\subsection{Judgment modification}

Let us suppose that a reciprocal matrix $A$ is obtained from a stakeholder judgment and the consistent matrix $A^{c}=E\left(p_{n}(L(A))\right)$ closest to $A$ is calculated. Perhaps this actor does not completely 
agree that the entries in $A^{c}$ fully represent his or her judgment. If the stakeholder decides to change, let us say, the entry $a_{r s}$ in $A^{c}$ comparing criteria $r$ and $s$ (where $r \neq s$ and $1 \leq r, s \leq n$ ), another reciprocal, probably non-consistent, matrix $B$ is obtained. The entries of $B$ compared with the entries of $A^{c}$ verify: $b_{r s}=\alpha a_{r s}$ and $b_{s r}=\alpha^{-1} a_{s r}$ for some $\alpha>0$, and $b_{i j}=a_{i j}$ in the remaining entries. In (Benítez et al., 2011b), we address the problem of finding the consistent matrix $B^{c}=E\left(p_{n}(L(B))\right)$ closest to $B$ by performing the lowest number of operations. Specifically, we show that

$$
B^{c}=A^{c} \otimes\left(x y^{T}\right),
$$

where $\otimes$ represent the Hadamard product of matrices, and $x$ and $y$ are the vectors defined by $x_{r}=$ $y_{s}=\alpha^{1 / n}, x_{s}=y_{r}=\alpha^{-1 / n}$, and $x_{i}=y_{i}$ when $i \neq r$ and $i \neq s$. Since the Hadamard product multiplies entries at the same positions, this process is easy to implement and has negligible computational burden.

\subsection{Consistent completion of an inconsistent matrix}

As some of the actors involved may not be completely familiar with all the criteria under consideration, it is common that the body of opinion is incomplete. To overcome this weakness, the authors have proposed (Benítez et al., 2013b) a framework that enables users to provide data on their preferences in a partial and/or incomplete way: the consistent completion of a reciprocal matrix as a mechanism to obtain a consistent body of opinion issued in an incomplete manner by a specific actor. This feature, described in the following paragraph, is incorporated into the process of linearization previously introduced and used in this paper to consistently complete partial information given by some of the stakeholders involved.

If a positive reciprocal matrix $A_{n \times n}$ with some unspecified (symmetrical) entries is provided, then $L(A)$ is defined up to a number of parameters, $\lambda_{1}, \ldots, \lambda_{k}$, with $k<<n$, corresponding to (half of) the unspecified entries: $L\left(A\left(\lambda_{1}, \ldots, \lambda_{k}\right)\right)$. The process then finds the values of $\lambda_{1}, \ldots, \lambda_{k}$ that minimize the distance of this matrix to $\mathcal{L}_{n}$. This minimization is performed (see Th. 4 of (Benítez et al., 2013b)) by a least square technique applied to a vectoral version of the matrix problem - involving a number of coefficients easily calculated from the entries of $A$ and the orthogonal basis $\left\{y_{1}, \ldots, y_{n-1}\right\}$ used in the linearization process. The solution of this least squares problem provides the values of $\lambda_{1}, \ldots, \lambda_{k}$, which enables the completed consistent matrix to be obtained.

\subsection{Trade-off between stakeholder(s) know-how and synthetic consistency}

The linearization method gives the matrix $A^{c}=E\left(p_{n}(L(A))\right)$ for $A$ positive and reciprocal, which is the closest consistent matrix to the original comparison matrix $A$. Nevertheless, the decision maker may not recognize $A^{c}$ as representative of his or her judgment. This matrix (with synthetic, forced, and artificial consistency) has been obtained in an attempt to improve consistency, but it may not be acceptable to the decision maker. Consequently, producing the priority vector directly from this matrix is generally incorrect, since it may be far from representing the real thoughts of the decision maker. The final priority must be obtained after a trade-off process that follows feedback from the decision maker until an expertise-consistency consensus is reached. As a consequence, the linearization method and its associated tools must be considered as auxiliary elements within the decision process: tools that push (blindly) toward consistency. The final priority vector will be the Perron eigenvector of the consensus matrix - provided that it has an acceptable consistency ratio.

The process described in Figure 1 contains a plausible iterative dialog between the stakeholder(s) and the consistency points of view and includes the described extensions: 


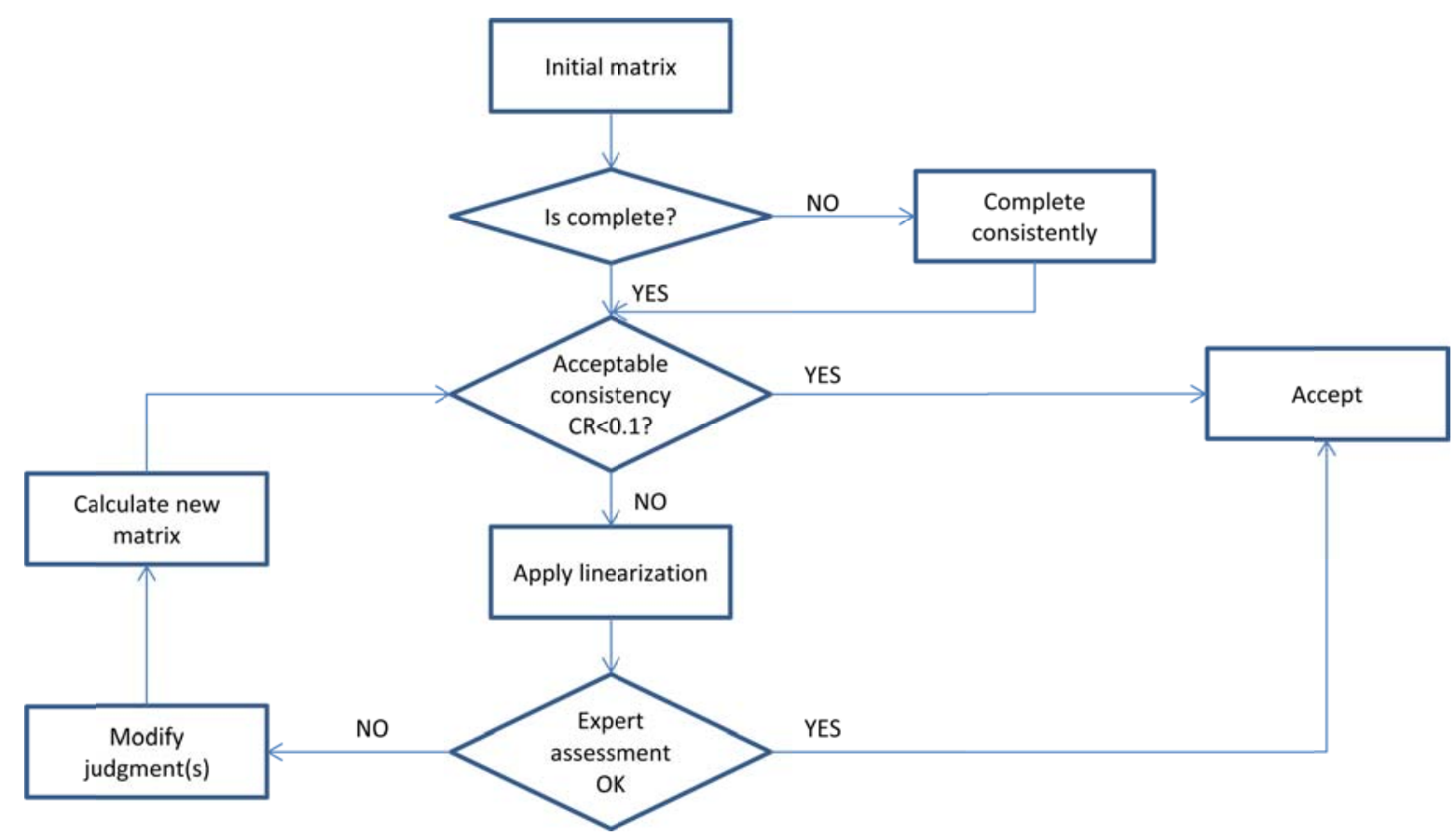

Figure 1. Chart flow for trade-off between stakeholder know-how and synthetic consistency

\subsection{Consensus among stakeholders}

AHP is known for its potential in group aggregation, or group modeling (Rouwette et al., 2002), or collaborative modeling (Maarten and Selvin, 1996; Rittgen, 2007) because of its flexibility and the availability of mathematical axiomatic principles in the aggregation of individual preferences and priorities to obtain the group preferences and priorities. There are two important aspects to address when using AHP in a multi-actor decision making process: firstly, how to combine individual judgments into a group judgment; and secondly, how to construct a group preference from individual preferences (Saaty, 2008b). These aspects are clarified by answering the following questions (Guitouni and Martel, 1998): (i) does the group act together as a unit or as separate individuals? (ii) which aggregation procedure is used to combine individual judgments? (iii) how can individual weights in the aggregations be obtained and incorporated if stakeholder judgments are not considered equally important?

With respect to the first question, we considered the views of six stakeholders, namely, the general manager of the Silao-Romita COTAS council, two users (irrigation and urban water users, respectively) who are members of the board of the COTAS council; a senior lecturer at the University of Guanajuato currently carrying out research in the study area; and two CEAG officials at different levels of responsibility. The stakeholders act as separate individuals.

Unlike the aggregation of individual judgments (AIJ) technique in which the group normally becomes a 'new individual'; in the aggregation of individual priorities (AIP) technique, individuals act in their own right with different value systems - thus resulting in alternative individual priorities (Forman and Peniwati, 1998). To aggregate the individual priorities into group priorities, arithmetic mean methods (AMM) or geometric mean methods (GMM) are mainly used. In both cases, weights can be used to give different importance to stakeholder judgments.

Finally, regarding question (iii) we have conducted an AHP-like survey among the same stakeholders so they can give opinions about how much importance they should have in the task of decision-making. The same tools previously described are used to obtain a consensus weighting vector to suitably weight their individual opinions. We also compare the results obtained with the aggregation performed using equal weights.

Below, we complement the answers to questions (i) and (iii) in suitable places. 


\section{Case study}

The Silao-Romita aquifer is located in the central-western state of Guanajuato in central Mexico (Figure 2); it includes the Guanajuato River sub-basin and has an area of 195,242 ha. It includes the municipalities of Silao and Romita, with the cities of Guanajuato and Irapuato to the east and south respectively.
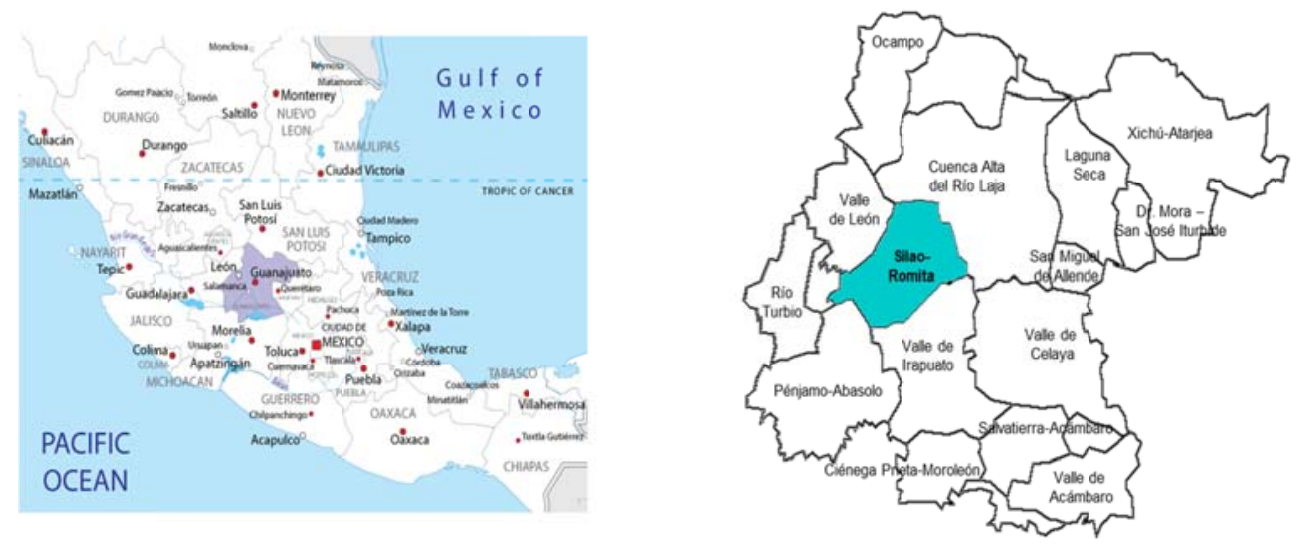

Figure 2. Location of the aquifer

By the end of 1990 there were 1984 water use points in the area, of which 1592 were active. These water uses were distributed as follows: 1390 irrigation, 176 drinking water, 15 industry, and 11 troughs (CEASG, 1998). A groundwater balance was held for the valley and for the deep aquifer, resulting in a charge of $130.29 \mathrm{Mm} 3 /$ year, a discharge of $305.4 \mathrm{Mm} 3 / \mathrm{year}$, an infiltration of 141.80 $\mathrm{Mm} 3 /$ year, and a negative change of storage of $33.33 \mathrm{Mm} 3 /$ year. The average annual abatement varies between 2 and 5 meters per year (CEASG, 1998). Based on these figures, the approximate value of the aquifer abatement in 2012 would be between 30 and 70 meters compared to 1998 data.

\subsection{Background}

Article 13-bis.1 of the National Water Act (LAN) provides for the establishment of a council for each river basin or watershed group. It also states that basin commissions, basin committees and COTAS groundwater technical committees shall assist these councils in the performance of their duties. This legislation also states that each watershed council is responsible for establishing the rules of composition, organization, and operation. To this end, the Lerma Chapala Basin Council, which includes the study area, established in its rules of operation that the goal of the COTAS council is the formulation, promotion, and monitoring of programs and actions that contribute to the stabilization and eventual recovery of overexploited aquifers, as well as to the preservation of those that are in balance and even those that have a greater recharge than extraction [CCLCH, 2010].

CONAGUA promoted the creation of the COTAS council to help meet the challenge of managing groundwater resources, especially in some 100 overexploited aquifers. In Guanajuato, each COTAS council has been supported by the state government since 1988 (through a trust called FIPASMA). The board of each COTAS council consists exclusively of groundwater users. Its personnel run a work program agreed annually with the CEAG and supported by FIPASMA (Foster et al., 2004; Foster and Garduño, 2009). The COTAS councils provide opportunities for consultation with users where programs and groundwater management models are implemented (Sandoval, 2004). However, Wester et al. (2011) believe that if the COTAS councils are to be effective, then they must be given greater responsibilities and become 'social auditors' for CONAGUA; and that their work must contribute to the activities of water management. Moreover, the COTAS council authority should be required to report irregularities committed by users, taking 
into account that their assigned objectives remain unreached (Wester et al., 2009) under the current operating scheme.

CONAGUA and CEAG began the first stage of an integral system of sustainable management of aquifers (SIMSA) in 2009. This project incorporates government and social actors in the task of defining, controlling, and managing water aquifers; as well as regulating the exploitation of water in the aquifer, and preserving the aquifer water quality and quantity. Sustainability is to be considered as a process of continuous improvement through the integrated management of water resources with social participation $(C E A G, 2012)$. To achieve these aims, an operational program for sustainable management of the aquifer (POMSA) must be developed in each aquifer. In 2011 the focus and follow-up group (GES) of SIMSA was formalized, including representatives of environmental institutions at federal and state levels, as well as user representatives. Five POMSA programs were operating in 2012, one of them being the Silao-Romita aquifer.

\subsection{Initial analysis of the problem}

The first part of the study was started in (Delgado-Galván et al., 2012a). The first step of the analysis of the problem was to study existing records on the priorities of resource management at the beginning of the work of the COTAS council. This listing was compiled after several meetings with council members. The priorities in this initial list are those listed below in no particular order:

1. Compile and analyze agreements and laws.

2. Collect and classify a user registry.

3. Provide education on water efficiency: primary schools, users, and general public.

4. Repair leaks (urban use).

5. Improve efficiency of irrigation systems.

6. Promote the construction of treatment plants in Silao, Romita and Guanajuato.

7. Manage reforestation.

8. Develop mechanisms of rainwater harvesting.

9. Construction, rehabilitation, and maintenance of levees, canals, river beds and retained water (former dams).

10. Provide the Gavia dam with irrigation and/or beekeeping activities, and the Chichimequilla dam with recharging and drinking use.

11. Set extraction limits for each well.

12. Develop a program of low water use crops.

13. Encourage private participation in irrigation programs.

14. Develop mechanisms to encourage the efficient use and penalties for misuse of water.

15. Define the duty and responsibility of government.

16. Monitor growth of the towns and cities of Silao, Romita, Guanajuato and Irapuato.

After analyzing the results of the first study of the aquifer problems during the last 12 years, a new list of action plans to address the current problems of the users and the area was compiled. To support the implementation of this new list of priorities, regular meetings and discussions with lecturers and researchers from the Department of Geomatics and Hydraulics of the University of Guanajuato, as well as students studying for a master's degree in water sciences at the same university, council directors, and staff of the COTAS council and CEAG were held. The purpose of these consultations was to obtain a reliable overview of the problem. An additional advantage of 
having had the support of these professionals is that the University of Guanajuato is located in the area of the Silao-Romita aquifer, and many university personnel perform their research in this area. Moreover, the board of directors consists of users of this aquifer, and the COTAS staff have formed part of the board since its inception; and finally, CEAG manages SIMSA. Their participation is then worthwhile and rewarding as they have a direct relationship with the object of analysis.

After several meetings, it was agreed to restrict the list to nine possible action plans. The action plans represent the current needs of users and the study area:

C1. Collect data and regulations regarding the extraction of water at municipal, state, and federal levels - information center.

C2. Produce a user registry - database.

C3. Encourage the technological development of agriculture - modernization.

C4. Make the COTAS council self-financing - finance.

C5. Restore and manage natural resources in the area - micro-catchments.

C6. Contribute to aquifer regulation - regulations.

C7. Communicate results of hydrological studies, work plans, and issues of interest to groups, associations, institutions and the general assembly of COTAS - dissemination.

C8. Encourage the design, construction, and maintenance of wastewater treatment plants pollution.

C9. Mediate in water conflicts - conflicts.

The rationale for each action plan can be found in (Delgado et al., 2012b).

As a result of those meetings, the six stakeholder sectors involved were identified.

\section{AHP in action: stakeholders, software, and data issues}

The next step was to obtain the views of all the stakeholders on the action plans. To this end, we considered the views of six specific stakeholders: two CEAG officials at different levels of responsibility (coordinator and sub-coordinator) who participated in the SIMSA (stakeholders \#1 and \#2); the Silao-Romita COTAS council manager (stakeholder \#3); a lecturer at the University of Guanajuato currently carrying out research in the study area (stakeholder \#4); and two users (irrigation and urban water users, respectively) who are on the board of the Silao-Romita COTAS council (stakeholders \#5 and \#6).

The views of this particular panel are important for the following reasons: the COTAS manager, who has been in charge since its creation, is the promoter of efficient water use and is in close contact with all those who have a concession from CONAGUA to use water from the aquifer. It is important to note that the main uses of the Silao-Romita groundwater aquifer are agricultural and urban. For this reason, it was decided to rely specifically on the elected representatives from both groups of users; these users are in fact part of the COTAS steering council and are elected as representatives by all the aquifer users. The lecturer from the University of Guanajuato has devoted a great deal of her research to assessing the impacts of anthropogenic activities on the current state of the aquifer. The two members of the CEAG, as members of the SIMSA, have wide experience on the integration of governmental and social actors in order to understand, control, and manage water aquifers.

The trade-off process outlined in Figure 1 was performed for all the matrices (including criteria and alternatives matrices) that were obtained after the work with the stakeholders. The specific meetings with these selected stakeholder representatives were devoted to collecting the necessary data and lasted between one and three hours depending on the stakeholder consulted and the amount of trade-off performed. The technical aspects involved in the process have been implemented in a tool developed in MatLab. Figure 3 shows the GUI (graphical user interface) containing the problem elements. This tool has been intensively used to build the entire decisionmaking process. 


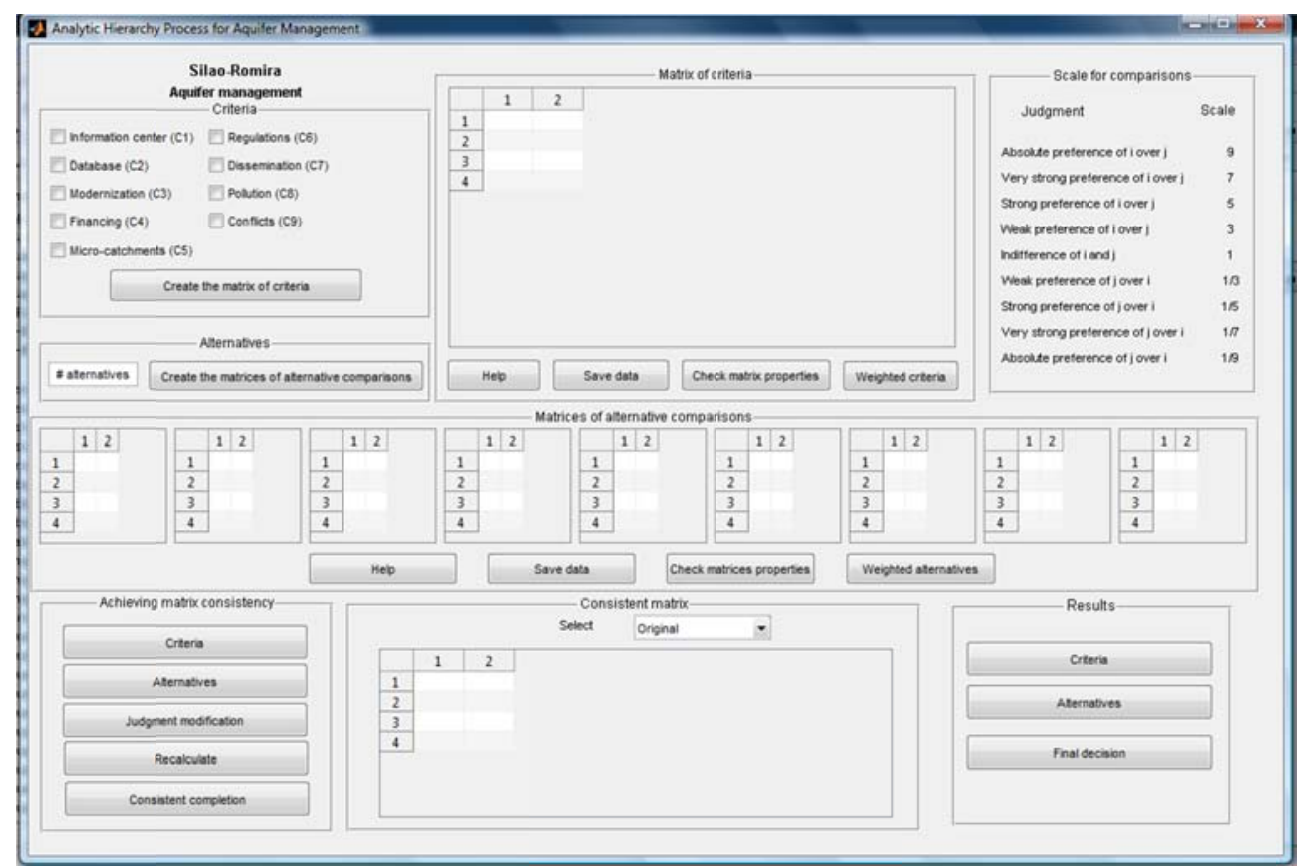

Figure 3. MatLab GUI for the AHP decision support system

\subsection{Comparison of criteria}

Tables 1 to 6 present the matrices of comparison of criteria for these six actors obtained after a series of meetings conducted by one of the authors (XDG) with the stakeholders involved in the study. Specific details of the trade-off process are described below and accompanied by the corresponding results: Perron eigenvector $\left(Z_{i}\right), \lambda_{\max i}$-value; consistency index $\left(C I_{i}\right)$; and consistency rate $\left(C R_{i}\right)$ for each matrix; $i=1$ to 6 and for the reached trade-off are also given. For each actor, the results that eventually prioritize the criteria are in bold.

\section{Stakeholder \#1}

Table 1. Matrix of comparison of criteria for stakeholder \#1

\begin{tabular}{|l|c|c|c|c|c|c|c|c|c|}
\hline & C1 & C2 & C3 & C4 & C5 & C6 & C7 & C8 & C9 \\
\hline C1 & 1 & $1 / 9$ & 1 & 5 & 3 & $1 / 7$ & 7 & 3 & 3 \\
\hline C2 & 9 & 1 & 3 & 5 & 5 & 1 & 7 & 3 & 5 \\
\hline C3 & 1 & $1 / 3$ & 1 & $1 / 7$ & 3 & 1 & 7 & 5 & 5 \\
\hline C4 & $1 / 5$ & $1 / 5$ & 7 & 1 & 3 & $1 / 3$ & 7 & $1 / 5$ & 3 \\
\hline C5 & $1 / 3$ & $1 / 5$ & $1 / 3$ & $1 / 3$ & 1 & $1 / 7$ & 7 & 3 & 5 \\
\hline C6 & 7 & 1 & 1 & 3 & 7 & 1 & 9 & 5 & 5 \\
\hline C7 & $1 / 7$ & $1 / 7$ & $1 / 7$ & $1 / 7$ & $1 / 7$ & $1 / 9$ & 1 & $1 / 7$ & $1 / 5$ \\
\hline C8 & $1 / 3$ & $1 / 3$ & $1 / 5$ & 5 & $1 / 3$ & $1 / 5$ & 7 & 1 & 3 \\
\hline C9 & $1 / 3$ & $1 / 5$ & $1 / 5$ & $1 / 3$ & $1 / 5$ & $1 / 5$ & 5 & $1 / 3$ & 1 \\
\hline
\end{tabular}

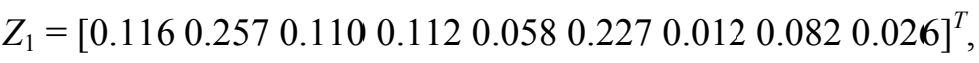

$$
\begin{aligned}
& \lambda_{\max 1}=12.33 ; C I_{1}=0.416 ; C R_{1}=28.7 \% \text {. }
\end{aligned}
$$


In this case, since $C R$ is greater than $10 \%$, a re-ordering is performed after returning to the actor (Aznar and Guijarro, 2008); consistency is then improved by linearization, approved by the actor, and the following prioritization vector is eventually obtained:

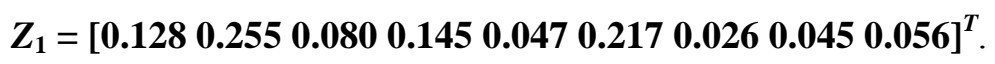

$\underline{\text { Stakeholder \#2 }}$

Table 2. Matrix of comparison of criteria for stakeholder \#2

\begin{tabular}{|c|c|c|c|c|c|c|c|c|c|}
\hline & C1 & C2 & C3 & C4 & C5 & C6 & C7 & C8 & C9 \\
\hline C1 & 1 & 5 & 1 & $1 / 3$ & 5 & 3 & 5 & 5 & 5 \\
\hline C2 & $1 / 5$ & 1 & 1 & 1 & 3 & 1 & 1 & 3 & 1 \\
\hline C3 & 1 & 1 & 1 & 5 & 1 & 1 & 1 & 1 & 3 \\
\hline C4 & 3 & 1 & $1 / 5$ & 1 & 3 & 1 & 1 & 3 & 5 \\
\hline C5 & $1 / 5$ & $1 / 3$ & 1 & $1 / 3$ & 1 & 1 & 1 & 7 & 1 \\
\hline C6 & $1 / 3$ & 1 & 1 & 1 & 1 & 1 & 1 & 5 & 5 \\
\hline C7 & $1 / 5$ & 1 & 1 & 1 & 1 & 1 & 1 & 3 & 1 \\
\hline C8 & $1 / 5$ & $1 / 3$ & 1 & $1 / 3$ & $1 / 7$ & $1 / 5$ & $1 / 3$ & 1 & 1 \\
\hline C9 & $1 / 5$ & 1 & $1 / 3$ & $1 / 5$ & 1 & $1 / 5$ & 1 & 1 & 1 \\
\hline
\end{tabular}

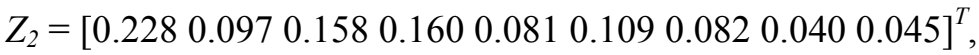

$$
\begin{aligned}
& \lambda_{\max 2}=10.94 ; C I_{2}=0.242 ; C R_{2}=16.7 \% \text {. }
\end{aligned}
$$

In this case, since the consistency rate is not too bad, only the linearization process was applied. The following prioritization vector, in agreement with the stakeholder, is then obtained:

$$
Z_{2}=\left[\begin{array}{lllllllll}
0.250 & 0.085 & 0.117 & 0.149 & 0.083 & 0.156 & 0.078 & 0.039 & 0.043
\end{array}\right]^{T} .
$$

$\underline{\text { Stakeholder \#3 }}$

Table 3. Matrix of comparison of criteria for stakeholder \#3

\begin{tabular}{|c|c|c|c|c|c|c|c|c|c|}
\hline & C1 & C2 & C3 & C4 & C5 & C6 & C7 & C8 & C9 \\
\hline C1 & 1 & 3 & $1 / 3$ & $1 / 5$ & $1 / 7$ & $1 / 9$ & 3 & $1 / 7$ & 3 \\
\hline C2 & $1 / 3$ & 1 & 3 & $1 / 7$ & $1 / 7$ & $1 / 9$ & 3 & $1 / 7$ & 3 \\
\hline C3 & 3 & $1 / 3$ & 1 & 9 & 3 & $1 / 9$ & 3 & $1 / 5$ & 5 \\
\hline C4 & 5 & 7 & $1 / 9$ & 1 & 9 & 9 & 9 & 9 & 9 \\
\hline C5 & 7 & 7 & $1 / 3$ & $1 / 9$ & 1 & $1 / 9$ & 7 & 7 & 9 \\
\hline C6 & 9 & 9 & 9 & $1 / 9$ & 9 & 1 & 9 & 9 & 9 \\
\hline C7 & $1 / 3$ & $1 / 3$ & $1 / 3$ & $1 / 9$ & $1 / 7$ & $1 / 9$ & 1 & 3 & 3 \\
\hline C8 & 7 & 7 & 5 & $1 / 9$ & $1 / 7$ & $1 / 9$ & $1 / 3$ & 1 & 5 \\
\hline C9 & $1 / 3$ & $1 / 3$ & $1 / 5$ & $1 / 9$ & $1 / 9$ & $1 / 9$ & $1 / 3$ & $1 / 5$ & 1 \\
\hline
\end{tabular}




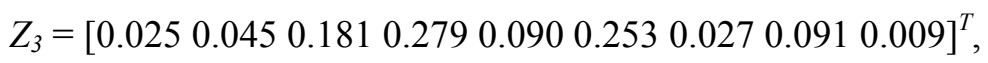

$$
\begin{aligned}
& \lambda_{\max 3}=17.8 ; C I_{3}=1.1 ; C R_{3}=75.9 \% .
\end{aligned}
$$

As the $C R$ is too high, another re-ordering of criteria is performed. The actor was then prompted to repeat the exercise. In this second iteration, values of $\lambda_{\max 3}=13.23, C I_{3}=0.53$ and $C R_{3}=36.5 \%$ were obtained. As the consistency rate was not yet acceptable the linearization method was applied. As a result, with the actor's agreement, the priority vector obtained was:

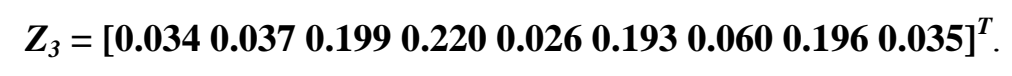

$\underline{\text { Stakeholder \#4 }}$

Table 4. Matrix of comparison of criteria for stakeholder \#4

\begin{tabular}{|c|c|c|c|c|c|c|c|c|c|}
\hline & C1 & C2 & C3 & C4 & C5 & C6 & C7 & C8 & C9 \\
\hline C1 & 1 & $1 / 6$ & $1 / 8$ & $1 / 9$ & $1 / 7$ & $1 / 6$ & 5 & 7 & $1 / 5$ \\
\hline C2 & 6 & 1 & $1 / 5$ & $1 / 9$ & $1 / 7$ & $1 / 6$ & 5 & $1 / 5$ & $1 / 3$ \\
\hline C3 & 8 & 5 & 1 & $1 / 5$ & 3 & $1 / 5$ & 9 & 5 & 7 \\
\hline C4 & 9 & 9 & 5 & 1 & 7 & 1 & 9 & 5 & 7 \\
\hline C5 & 7 & 7 & $1 / 3$ & $1 / 7$ & 1 & $1 / 5$ & 9 & 3 & 7 \\
\hline C6 & 6 & 6 & 5 & 1 & 5 & 1 & 9 & 7 & 7 \\
\hline C7 & $1 / 5$ & $1 / 5$ & $1 / 9$ & $1 / 9$ & $1 / 9$ & $1 / 9$ & 1 & $1 / 6$ & $1 / 5$ \\
\hline C8 & $1 / 7$ & 5 & $1 / 5$ & $1 / 5$ & $1 / 3$ & $1 / 7$ & 6 & 1 & 7 \\
\hline C9 & 5 & 3 & $1 / 7$ & $1 / 7$ & $1 / 7$ & $1 / 7$ & 5 & $1 / 7$ & 1 \\
\hline
\end{tabular}

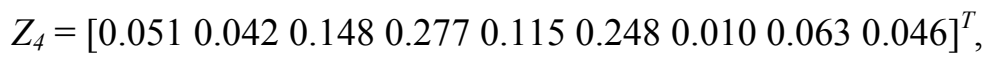

$$
\begin{aligned}
& \lambda_{\max 4}=13.08 ; C I_{4}=0.51 ; C R_{4}=35.2 \% .
\end{aligned}
$$

Given this rate of consistency, the actor was informed about how to continue. The actor decided to follow an initial re-ordering and to provide new judgments at a later time. For the obtained matrix, values of $\lambda_{\text {máx }}=11.78, C I_{4}=0.35$ and $C R_{4}=24 \%$ were obtained. The linearization process, once more with the agreement with the actor, produced the following prioritization vector:

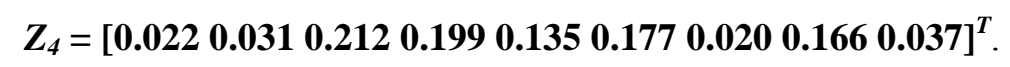

$\underline{\text { Stakeholder \#5 }}$

Table 5. Matrix of comparison of criteria for stakeholder \#5

\begin{tabular}{|c|c|c|c|c|c|c|c|c|c|}
\hline & C1 & C2 & C3 & C4 & C5 & C6 & C7 & C8 & C9 \\
\hline C1 & 1 & 3 & $1 / 9$ & $1 / 9$ & $1 / 3$ & 3 & $1 / 3$ & 3 & 3 \\
\hline C2 & $1 / 3$ & 1 & $1 / 9$ & $1 / 9$ & 5 & $1 / 7$ & 5 & 3 & 3 \\
\hline C3 & 9 & 9 & 1 & 5 & 9 & 7 & 9 & 9 & 9 \\
\hline C4 & 9 & 9 & $1 / 5$ & 1 & 5 & 3 & 9 & 7 & 5 \\
\hline C5 & 3 & $1 / 5$ & $1 / 9$ & $1 / 5$ & 1 & $1 / 5$ & 1 & 3 & 5 \\
\hline C6 & $1 / 3$ & 7 & $1 / 7$ & $1 / 3$ & 5 & 1 & 5 & $1 / 3$ & $*$ \\
\hline
\end{tabular}




\begin{tabular}{|c|c|c|c|c|c|c|c|c|c|}
\hline C7 & 3 & $1 / 5$ & $1 / 9$ & $1 / 9$ & 1 & $1 / 5$ & 1 & $1 / 3$ & $1 / 3$ \\
\hline C8 & $1 / 3$ & $1 / 3$ & $1 / 9$ & $1 / 7$ & $1 / 3$ & 3 & 3 & 1 & 1 \\
\hline C9 & $1 / 3$ & $1 / 3$ & $1 / 9$ & $1 / 5$ & $1 / 5$ & $*$ & 3 & 1 & 1 \\
\hline
\end{tabular}

In this case, the stakeholder refused to provide a judgment with respect to two elements of the problem: regulations (C6) and conflicts (C9). This was because this specific actor believed that there would be no conflicts if proper regulations and compliance existed. Therefore, the comparison between those criteria was left blank. We then resourced the termination of the incomplete judgments technique described above. The vector of priorities for the consistently completed matrix is:

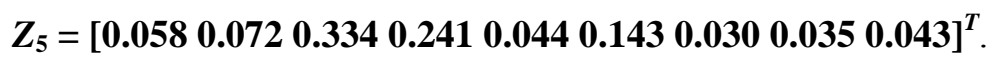

$\underline{\text { Stakeholder \#6 }}$

Table 6a. Matrix of comparison of criteria for stakeholder \#6

\begin{tabular}{|c|c|c|c|c|c|c|c|c|c|}
\hline & C1 & C2 & C3 & C4 & C5 & C6 & C7 & C8 & C9 \\
\hline C1 & 1 & $1 / 5$ & $1 / 7$ & $1 / 8$ & $1 / 5$ & $1 / 3$ & 1 & $1 / 6$ & $1 / 3$ \\
\hline C2 & 5 & 1 & $1 / 5$ & $1 / 5$ & $1 / 3$ & 1 & 3 & $1 / 5$ & 3 \\
\hline C3 & 7 & 5 & 1 & 1 & 3 & 1 & 7 & 1 & 3 \\
\hline C4 & 8 & 5 & 1 & 1 & 3 & 1 & 7 & 1 & 3 \\
\hline C5 & 5 & 3 & $1 / 3$ & $1 / 3$ & 1 & $1 / 3$ & 7 & $1 / 3$ & 3 \\
\hline C6 & 3 & 1 & 1 & 1 & 3 & 1 & 9 & $1 / 3$ & $1 / 3$ \\
\hline C7 & 1 & $1 / 3$ & $1 / 7$ & $1 / 7$ & $1 / 7$ & $1 / 9$ & 1 & $1 / 7$ & $1 / 5$ \\
\hline C8 & 6 & 5 & 1 & 1 & 3 & 3 & 7 & 1 & 3 \\
\hline C9 & 3 & $1 / 3$ & $1 / 3$ & $1 / 3$ & $1 / 3$ & 3 & 5 & $1 / 3$ & 1 \\
\hline
\end{tabular}

In this case, the following results were obtained from the original matrix:

$$
\begin{gathered}
Z_{6}=\left[\begin{array}{c}
0.0220 .0740 .1860 .1890 .1020 .1180 .0190 .2070 .083
\end{array}\right]^{T}, \\
\lambda_{\max 6}=10.25 ; C I_{6}=0.157 ; C R_{6}=10.8 \% .
\end{gathered}
$$

As the $C R$ is close to $10 \%$, it was suggested to the stakeholder to approve the matrix or to perform the linearization process. After performing this process the matrix in Table $6 \mathrm{~b}$ was obtained:

Table 6b. Second matrix of comparison of criteria for stakeholder \#6

\begin{tabular}{|c|c|c|c|c|c|c|c|c|c|}
\hline & C1 & C2 & C3 & C4 & C5 & C6 & C7 & C8 & C9 \\
\hline C1 & 1.00 & 0.53 & 0.15 & 0.14 & 0.20 & 0.20 & 1.20 & 0.15 & 0.35 \\
\hline C2 & 1.88 & 1.00 & 0.28 & 0.26 & 0.38 & 0.37 & 2.26 & 0.28 & 0.66 \\
\hline C3 & 6.81 & 3.62 & 1.00 & 0.95 & 1.38 & 1.34 & 8.18 & 1.03 & 2.41 \\
\hline C4 & 7.14 & 3.79 & 1.05 & 1.00 & 1.45 & 1.41 & 8.57 & 1.07 & 2.52 \\
\hline C5 & 4.92 & 2.61 & 0.72 & 0.69 & 1.00 & 0.97 & 5.91 & 0.74 & 1.74 \\
\hline
\end{tabular}




\begin{tabular}{|l|l|l|l|l|l|l|l|l|l|}
\hline C6 & 5.07 & 2.69 & 0.74 & 0.71 & 1.03 & 1.00 & 6.09 & 0.76 & 1.79 \\
\hline C7 & 0.83 & 0.44 & 0.12 & 0.12 & 0.17 & 0.16 & 1.00 & 0.13 & 0.29 \\
\hline C8 & 6.64 & 3.53 & 0.97 & 0.93 & 1.35 & 1.31 & 7.98 & 1.00 & 2.35 \\
\hline C9 & 2.83 & 1.50 & 0.42 & 0.40 & 0.58 & 0.56 & 3.40 & 0.43 & 1.00 \\
\hline
\end{tabular}

This consistent matrix was unsatisfactory for the stakeholder as some of the comparison values did not reflect his/her opinion, particularly comparisons of contamination (C8) with modernization (C3) and financing (C4). To complete this application, we used the technique described above to modify the judgments, and thus obtained the following prioritization vector:

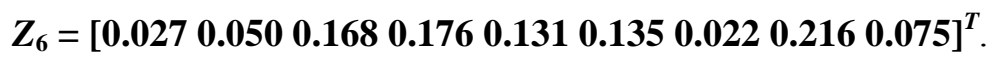

It is important to note that close contact was maintained with the stakeholders during each of the processes. They looked at the changes in the matrix of criteria comparison and analyzed the eigenvectors. In other words, the changes undergone following the individual comparison of items were examined together with the changes taking place in the priority vectors.

\subsection{Comparison of alternatives}

Given the experience gathered during the years and the stress developed among the various organizations involved in aquifer management, three alternatives were proposed to define the future management framework in terms of user benefit and environmental sustainability.

G1. Combined management by CONAGUA-CEAG-COTAS with mutual economic independence

G2. Management by the COTAS council

\section{G3. Combined management CONAGUA-CEAG}

The next step was the analysis of the alternatives given by the actors. We now consider a comparison of alternatives for each criterion developed by the six actors, and provide comments about their consistency and the manipulations performed to obtain alternative priority vectors.

Table 7. Matrices of comparison of alternatives by stakeholder \#1

\begin{tabular}{|c|c|c|c|c|}
\hline C1 & G1 & G2 & G3 & eig \\
\hline G1 & 1 & 3 & 3 & 0.58 \\
\hline G2 & $1 / 3$ & 1 & 3 & 0.28 \\
\hline G3 & $1 / 3$ & $1 / 3$ & 1 & 0.14 \\
\hline
\end{tabular}

\begin{tabular}{|c|c|c|c|c|}
\hline C2 & G1 & G2 & G3 & eig \\
\hline G1 & 1 & 3 & $1 / 3$ & 0.28 \\
\hline G2 & $1 / 3$ & 1 & $1 / 3$ & 0.14 \\
\hline G3 & 3 & 3 & 1 & 0.58 \\
\hline
\end{tabular}

\begin{tabular}{|c|c|c|c|c|}
\hline C3 & G1 & G2 & G3 & Eig \\
\hline G1 & 1 & 5 & $1 / 3$ & 0.30 \\
\hline G2 & $1 / 5$ & 1 & $1 / 5$ & 0.09 \\
\hline G3 & 3 & 5 & 1 & 0.62 \\
\hline
\end{tabular}

\begin{tabular}{|c|c|c|c|c|}
\hline C4 & G1 & G2 & G3 & eig \\
\hline G1 & 1 & 3 & $1 / 3$ & 0.26 \\
\hline G2 & $1 / 3$ & 1 & $1 / 5$ & 0.10 \\
\hline G3 & 3 & 5 & 1 & 0.64 \\
\hline
\end{tabular}

\begin{tabular}{|c|c|c|c|c|}
\hline C5 & G1 & G2 & G3 & eig \\
\hline G1 & 1 & 3 & $1 / 3$ & 0.26 \\
\hline G2 & $1 / 3$ & 1 & $1 / 5$ & 0.10 \\
\hline G3 & 3 & 5 & 1 & 0.64 \\
\hline
\end{tabular}

\begin{tabular}{|c|c|c|c|c|}
\hline C6 & G1 & G2 & G3 & Eig \\
\hline G1 & 1 & 3 & $1 / 3$ & 0.28 \\
\hline G2 & $1 / 3$ & 1 & $1 / 3$ & 0.14 \\
\hline G3 & 3 & 3 & 1 & 0.58 \\
\hline
\end{tabular}

\begin{tabular}{|c|c|c|c|c|}
\hline C7 & G1 & G2 & G3 & eig \\
\hline G1 & 1 & $1 / 3$ & $1 / 5$ & 0.10 \\
\hline G2 & 3 & 1 & $1 / 5$ & 0.20 \\
\hline G3 & 5 & 5 & 1 & 0.70 \\
\hline
\end{tabular}

\begin{tabular}{|c|c|c|c|c|}
\hline C8 & G1 & G2 & G3 & eig \\
\hline G1 & 1 & $1 / 7$ & $1 / 5$ & 0.07 \\
\hline G2 & 7 & 1 & $1 / 7$ & 0.22 \\
\hline G3 & 5 & 7 & 1 & 0.71 \\
\hline
\end{tabular}

\begin{tabular}{|c|c|c|c|c|}
\hline C9 & G1 & G2 & G3 & Eig \\
\hline G1 & 1 & 7 & $1 / 5$ & 0.24 \\
\hline G2 & $1 / 7$ & 1 & $1 / 7$ & 0.06 \\
\hline G3 & 5 & 7 & 1 & 0.70 \\
\hline
\end{tabular}

The original matrices containing the opinions of stakeholder \#1 regarding the management alternatives for the Silao-Romita aquifer based on each of the nine criteria are given in Table 7. The eigenvector for each matrix is also presented in the column labeled with 'eig'. 
In this specific case, all these matrices, except for those corresponding to $\mathrm{C} 4$ and $\mathrm{C} 5$, with $C R=$ $3.7 \%$, exceed the $10 \%$ of consistency rate. After applying the linearization process and going back for stakeholder approval, the new priority vectors are the ordered columns of the matrix

$$
G_{1}=\left(\begin{array}{lllllllll}
0.55 & 0.29 & 0.41 & 0.26 & 0.26 & 0.29 & 0.13 & 0.12 & 0.42 \\
0.29 & 0.15 & 0.09 & 0.10 & 0.10 & 0.15 & 0.16 & 0.13 & 0.07 \\
0.15 & 0.55 & 0.50 & 0.64 & 0.64 & 0.55 & 0.71 & 0.75 & 0.52
\end{array}\right) .
$$

By aggregating these priorities with the criteria priority given by $\boldsymbol{Z}_{\mathbf{1}}$ (achieved by multiplying $G_{1} \boldsymbol{Z}_{1}$ ) the ranking of alternatives for stakeholder $\# 1$ is obtained:

$$
W_{1}=(0.3234,0.1513,0.5253)^{T} .
$$

This same process was carried out with all the actors. For the sake of simplicity, we do not provide all of the information. The following matrices, $G_{i}$, show by columns the priority vectors corresponding to the ordered alternatives for the rest of the actors, $i=2, \ldots, 6$; and the corresponding aggregated priorities are given by the vectors $W_{i}$.

$$
\begin{aligned}
& G_{2}=\left(\begin{array}{lllllllll}
0.10 & 0.09 & 0.26 & 0.24 & 0.09 & 0.14 & 0.10 & 0.13 & 0.48 \\
0.10 & 0.14 & 0.11 & 0.09 & 0.14 & 0.09 & 0.13 & 0.12 & 0.08 \\
0.80 & 0.76 & 0.64 & 0.67 & 0.76 & 0.76 & 0.77 & 0.75 & 0.45
\end{array}\right) \\
& W_{2}=(0.1619,0.1069,0.7311)^{T} . \\
& G_{3}=\left(\begin{array}{lllllllll}
0.06 & 0.13 & 0.08 & 0.14 & 0.07 & 0.06 & 0.06 & 0.10 & 0.11 \\
0.58 & 0.08 & 0.79 & 0.77 & 0.40 & 0.58 & 0.63 & 0.12 & 0.80 \\
0.36 & 0.79 & 0.13 & 0.09 & 0.54 & 0.36 & 0.31 & 0.78 & 0.09
\end{array}\right) \\
& W_{3}=(0.0933,0.5607,0.3459)^{T} . \\
& G_{4}=\left(\begin{array}{lllllllll}
0.09 & 0.10 & 0.09 & 0.36 & 0.09 & 0.10 & 0.08 & 0.10 & 0.08 \\
0.24 & 0.77 & 0.67 & 0.06 & 0.67 & 0.08 & 0.73 & 0.13 & 0.73 \\
0.67 & 0.13 & 0.24 & 0.58 & 0.24 & 0.82 & 0.19 & 0.77 & 0.19
\end{array}\right) \\
& W_{4}=(0.1469,0.3522,0.5009)^{T} . \\
& G_{5}=\left(\begin{array}{ccccccccc}
0.11 & 0.33 & 0.82 & 0.80 & 0.42 & 0.77 & 0.66 & 0.42 & 0.16 \\
0.17 & 0.26 & 0.09 & 0.11 & 0.14 & 0.09 & 0.14 & 0.33 & 0.71 \\
0.71 & 0.41 & 0.10 & 0.09 & 0.43 & 0.13 & 0.20 & 0.25 & 0.13
\end{array}\right) \\
& W_{5}=(0.6671,0.1499,0.1830)^{T} .
\end{aligned}
$$

In this case, this specific stakeholder decided to leave three matrices incomplete, since he had no developed opinion to fully complete the comparison of alternatives regarding the criteria of financing (C4), micro-catchment (C5), and pollution (C8). The consistent completion technique was accordingly used.

$$
\begin{gathered}
G_{6}=\left(\begin{array}{ccccccccc}
0.50 & 0.32 & 0.28 & 0.49 & 0.65 & 0.75 & 0.50 & 0.67 & 0.51 \\
0.09 & 0.13 & 0.07 & 0.07 & 0.07 & 0.07 & 0.05 & 0.09 & 0.10 \\
0.41 & 0.54 & 0.65 & 0.44 & 0.28 & 0.18 & 0.44 & 0.24 & 0.39
\end{array}\right) \\
W_{6}=(0.5436,0.0794,0.3770)^{T} .
\end{gathered}
$$

As in the case of stakeholder \#1, the trade-off process described in Figure 1 was used to obtain a complete expertise-consistency consensus for each actor. Taking into account that these matrices are sized $3 \times 3$ it is worth noting that in only a few cases was a complete cycle of negotiation with the stakeholder necessary. 


\section{Results and discussion}

After individually analyzing the elements of the problem (the management alternatives for the Silao-Romita aquifer, the consistency evaluation, and the changes needed to validate the AHP method) we aggregated the results to extract the information.

Two types of result are of interest. Firstly, just the ranking of the considered criteria will reveal the prioritization of the current needs of the area and its users and, consequently, the prioritization for the action to be taken. Secondly, we will consider the whole process in order to assess the alternatives under consideration.

For both studies we present the results in two cases: 1) all the stakeholder opinions are given the same importance; 2) the stakeholder opinions are suitably weighted.

Finally, in both cases, we use both arithmetic and geometric mean aggregation. Four aggregation methods, namely, AMM, WAMM, GMM and WGMM, are used.

The stakeholder weights, after an AHP-like process in which each stakeholder was asked to give pairwise judgments comparing the importance of the opinion of any stakeholder with respect to any other stakeholder, reveal opinions about the importance assigned to the decision-making problem in hand (see Table 8). The first six columns present the priorities obtained from each actor with respect to the whole pool and are shown in the same order as the headings given for the first six columns. The last two columns show the AMM and the GMM (normalized to 1) of these weights.

Table 8. Judgment importance weights (self-attributed by the stakeholders)

\begin{tabular}{|r|r|r|r|r|rrr|}
\hline Manager & \multicolumn{1}{c|}{ CEAG1 } & \multicolumn{1}{c|}{$\begin{array}{c}\text { Univ. } \\
\text { Lect. }\end{array}$} & Agr. user & Urb. user & \multicolumn{1}{c|}{ CEAG } & AMM & GMM \\
\hline 0.312 & 0.051 & 0.199 & 0.027 & 0.038 & 0.045 & 0.112 & 0.099 \\
\hline 0.172 & 0.061 & 0.043 & 0.028 & 0.072 & 0.073 & 0.075 & 0.087 \\
\hline 0.199 & 0.047 & 0.023 & 0.037 & 0.048 & 0.053 & 0.068 & 0.072 \\
\hline 0.028 & 0.375 & 0.089 & 0.147 & 0.373 & 0.299 & 0.219 & 0.216 \\
\hline 0.034 & 0.351 & 0.089 & 0.132 & 0.373 & 0.418 & 0.233 & 0.229 \\
\hline 0.254 & 0.114 & 0.557 & 0.630 & 0.096 & 0.111 & 0.294 & 0.298 \\
\hline
\end{tabular}

The results show that the CEAG coordinator and the agricultural and urban users have a major influence, about $75 \%$, in decision-making: the remainder corresponding to the COTAS council manager, the sub-coordinator of the CEAG (CEAG1), and the senior lecturer of the University of Guanajuato.

The values of the AMM and GMM are very similar and have no influence on the other calculations. Thus, we will use the AMM values from now on.

We start by considering the criteria, and then the alternatives.

\subsection{Group prioritization of criteria}

Vectors $Z_{i}, i=1, \ldots, 6$ (given in bold in Subsection 4.1) are used in this case. With these vectors, AMM, WAMM, GMM and WGMM are calculated. These values are given, in descending order for AMM, in Table 9. 
Table 9. Group prioritization of criteria (action plans)

\begin{tabular}{|l|l|r|r|r|r|}
\hline \multicolumn{2}{|c|}{ Action plans } & AMM & GMM & WAMM & WGMM \\
\hline C4 & Finance & 0.189 & 0.211 & 0.186 & 0.208 \\
\hline C3 & Modernization & 0.185 & 0.191 & 0.181 & 0.181 \\
\hline C6 & Regulations & 0.170 & 0.191 & 0.172 & 0.192 \\
\hline C8 & Pollution & 0.116 & 0.099 & 0.107 & 0.089 \\
\hline C2 & Database & 0.088 & 0.076 & 0.115 & 0.097 \\
\hline C1 & Information center & 0.086 & 0.066 & 0.081 & 0.069 \\
\hline C5 & Micro-catchments & 0.078 & 0.074 & 0.072 & 0.070 \\
\hline C9 & Conflicts & 0.048 & 0.053 & 0.053 & 0.059 \\
\hline C7 & Dissemination & 0.039 & 0.039 & 0.033 & 0.034 \\
\hline
\end{tabular}

Even though these indices provide different priorities, including some very light rank reversals, the results agree overall, and provide, according to the stakeholder's opinions, an approximate ordering for the needs of the Silao-Romita aquifer. This prioritization of action plans can help solve the problems faced by the users and the environment.

The results show that the financing needs (C4), field modernization (C3), and regulations (C6) are the three most important needs. The stakeholders consider that funding (C4) is essential to carry out projects that will have an impact on the management of the resources of the aquifer and thus achieve stabilization. Furthermore, since farming demands the largest share of groundwater, specific actions are required for the efficient use of water - such as improved irrigation technology, change of crops, or even a change in productive activities (C3). The urgent need to establish the authority of the COTAS councils is also clear, since they have not achieved their goal of becoming a social base for encouraging the development, promotion, and monitoring of programs and actions that contribute to the stabilization and eventual recovery of aquifers. This is largely due to the imprecise definition of powers and responsibilities (C6).

Pollution (C8) has a major weight in the analysis of the problem and is of great interest for the stakeholders consulted. Pollution is related to regulations as the COTAS council does not have the authority to ensure compliance with regulations on discharges into water bodies. The same happens with the lack of compliance with concession titles and rights granted to farm users - the result is overexploitation.

The elements database $(\mathrm{C} 2)$, information center $(\mathrm{C} 1)$, and dissemination action plans $(\mathrm{C} 7)$ refer to the information needs, the systematization of information, and public access to this information. CONAGUA, CEAG, and COTAS must work together collecting data and the implementation of a comprehensive system that reaches users, institutions, and the general public. Note that even though these three elements appear in the second half of the prioritization list, they account for over $20 \%$ of the total.

In relation to the work needed to restore watersheds (C5), it is necessary to improve the forest conditions in the area and encourage the infiltration and maintenance of vegetation cover. Programs are needed in coordination with other government agencies for endemic species reforestation works, restoration of dikes, dams and reservoirs, etc. In addition, environmental uses and ecosystem services should be clearly recognized. However, the weight obtained in the analysis is not greater than $8 \%$. 
Conflicts (C9) obtained a weight lower than 5\%. Among the actions that SIMSA promotes, the need to seek new sources of supply to alleviate the competitive tensions between users is considered. For this reason, great interest has been shown in projects by the University of Guanajuato that search for alternative sources in the aquifer. Additionally, mechanisms should be established to facilitate user interaction so that they can voice problems. This interaction will enable users to receive advice for finding solutions. The State, in coordination with the COTAS council, can mediate if disputes arise.

\subsection{Group prioritization of alternatives}

Vectors $W_{i}, i=1, \ldots, 6$ (given in subsection 4.2) aggregate judgment with respect to the alternatives for each stakeholder and are used in this case. AMM, WAMM, GMM and WGMM are again calculated with these vectors. These values are given, in descending order for AMM, in Table 10.

Table 10. Group prioritization of alternatives

\begin{tabular}{|c|l|c|c|c|c|}
\hline \multicolumn{2}{|c|}{ (Management) alternatives } & AMM & GMM & WAMM & WGMM \\
\hline G3 & CONAGUA-CEAG-COTAS & 0.444 & 0.483 & 0.410 & 0.434 \\
\hline G1 & CONAGUA-CEAG & 0.323 & 0.299 & 0.400 & 0.386 \\
\hline G2 & COTAS & 0.233 & 0.217 & 0.190 & 0.179 \\
\hline
\end{tabular}

Again these indices provide different priorities. There is no rank reversal among them, and clearly the results agree overall and provide a stakeholder ranking among the proposed management alternatives.

According to the six stakeholders, the most sustainable management option for the users of the Silao-Romita aquifer and the environment is a shared management between CONAGUA, CEAG and the local COTAS council. Note that this is the scheme under which the aquifer is working currently. The second best option gives the management of the resources in the aquifer to COANGUA and CEAG. This would mean the disappearance of the COTAS council, either in its current form or, by integrating it within the structure of CEAG. The option with the lowest weight is an exclusive management by the COTAS council. This would imply the delegation of tasks and responsibilities by CONAGUA and CEAG and a change of regulations.

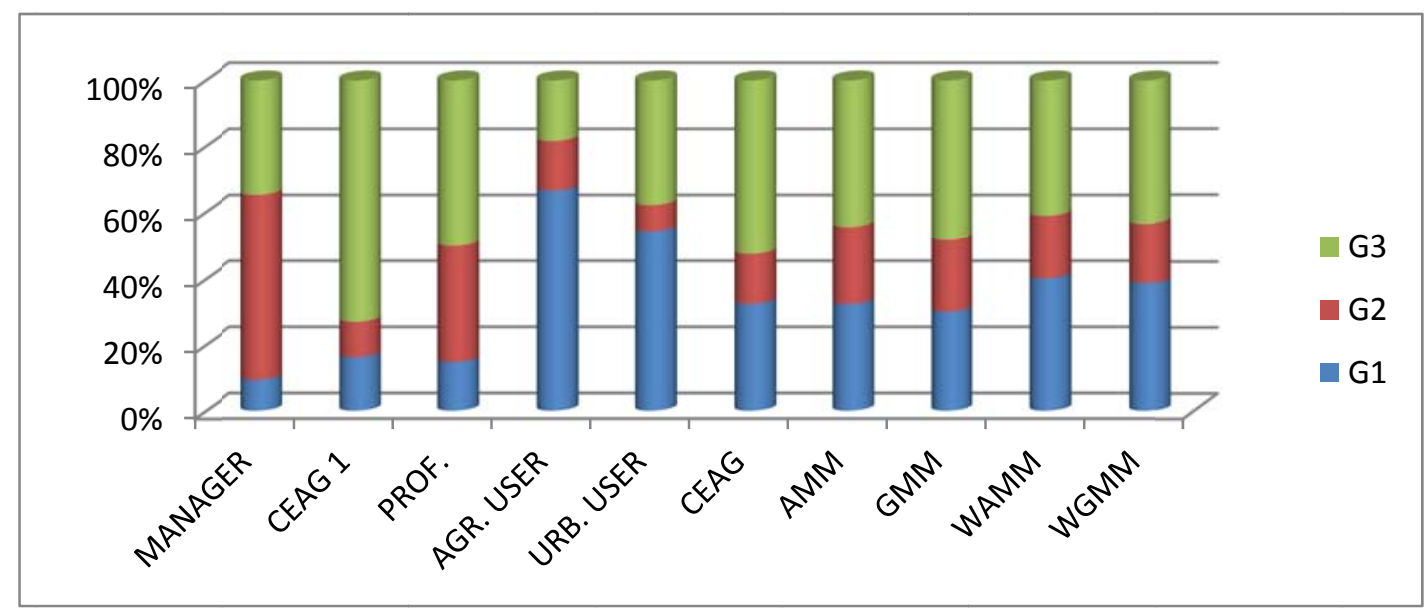

Figure 4. Priorities of the three alternatives given by individuals as well as those derived from four different group aggregation methodologies 
We have checked these aggregation processes against the two social choice axioms that any group aggregation must comply with, namely, Pareto optimality, and non-dictatorship axioms. Figure 4 shows the preferred options given by individuals and the group consensus in a graphical form.

From the above results it is apparent that all the indices satisfy the Pareto optimality axiom, which is a well accepted axiom for group aggregation. Figure 5 demonstrates the deviation of individual member priorities from the group consensus reached using AMM. Clearly, this aggregation follows the non-dictatorship axiom. Similar graphs may be drawn using the other aggregations methods with the same conclusion.

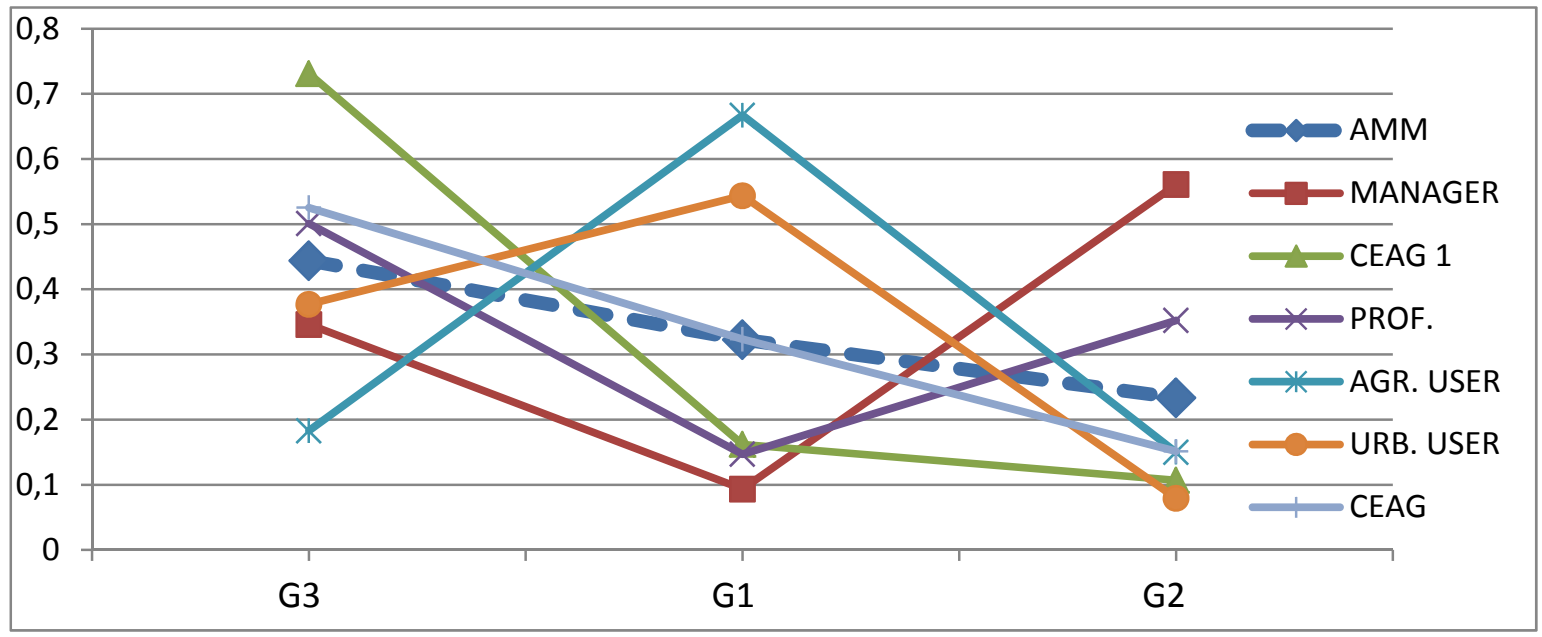

Figure 5. Deviation of individual member priorities from group consensus (AMM)

\subsection{Critical assessment of the used methodology}

To close the discussion we provide a number of ideas that can help situate the work performed and appraise the strengths and weaknesses of our approach. Given the size of the problem considered, this work could have hardly been developed from just a discursive approach. Firstly, judgment and opinions need to be written down to avoid a posteriori misunderstanding and biased shifts in opinion. Secondly, using a specific tool - after having made the effort of fully explaining it to each actor - was a guarantee for everyone that their opinions would be taken into consideration and given the same priority as everyone else's opinions. This gives everybody confidence in the methodology and so collaboration starts to be really productive.

A number of reasons compelled us to select swing AHP as the most suitable MCA method.

Firstly, AHP is a well established methodology for MCA that has been successfully applied in many fields such as environmental planning, energy design, social sciences, agriculture and marketing. The success of this method is a result of its simplicity and robustness (Vargas, 1990). Furthermore, another characteristic of AHP lies in its ability to handle both quantitative and qualitative judgments (Macharis et al., 2004), a feature that was not used in this work. Consistency tests can easily filter inconsistent judgments and so make the results reliable (Kablan, 2004). Moreover, the way in which consistency is assessed enables the quality of the judgment and the efficiency of the final decision to be ensured (Pohekar and Ramachandran, 2004).

Secondly, the AHP method is used generally in applications in which a small number of alternatives are involved, as is the case we have addressed. This fact clearly led us to consider AHP instead of other outranking approaches such as PROMETHEE and ELECTRE (methods that essentially involve holding various 'votes' across dimensions to eliminate the least voted alternatives). Macharis et al. (2004) analyzed the strengths and weaknesses of both PROMETHEE and AHP methods and concluded that a number of favorable characteristics of the AHP method could be used to improve outranking methods in general. In particular, they state that the criteria 
weights obtained by AHP, have a higher a level of coherence, correlation, consistency, and accuracy than weights determined on the basis of intuition or a domain specialist's knowledge (which is mostly used in the PROMETHEE method).

Last but not least, the authors have a certain expertise in AHP and have developed a number of tools that can be used in a straightforward and expeditious manner.

However, a major disadvantage of the method is that the implemented pairwise comparisons may become so numerous that the uncertainty of the process increases significantly (Macharis et al., 2004). As said above, this is not the case of our application, since it does not involve that many elements.

AHP generally has a number of significant advantages (Ishizaka and Ashraf, 2011). For example, it is a relatively simple method for decision makers. Furthermore, AHP builds on pairwise comparison data, especially in the subjective cases, and this is an attractive aspect that directly involves decision makers. Moreover, group AHP methods enable a group member's judgments about each facet of the decision problem to be captured. Subjective judgments on individual components of the decision problem are thus easily accommodated (Saaty and Peniwati, 2007).

\section{Conclusions}

With the application of the process described it is possible to analyze the problems of the aquifer, and to establish an order of priorities based on an exercise of reflection and a mathematical procedure - ensuring that the process is reliable and that the views of the stakeholders are useful in decision making. Moreover, the results serve as guidelines for priority actions aiming at solving the general problem of the study area.

Given the qualitative nature of our model, numeric evaluation metrics are not suitable. In contrast, a number of questions, as proposed in Section 5 of (Bennett et al., 2013), have been answered that validate the model outcomes. Some of the answers include the fact that the user community has been clearly identified; the model meets its specified purpose and behaved as expected; the model has proven to be flexible and transparent enough for stakeholders, and has improved their ability to understand the behavior of the aquifer (compared with the scarce knowledge some stakeholders had previously); the analysis of the problem of the aquifer is useful as a co-learning tool because it sets the basis for an exchange of points of view and an enrichment of the knowledge of the stakeholders; these dynamics favor communication between participants. In addition, the model has revealed several new facts about the system and the real needs of the study area and the users were eventually obtained with the agreement of the stakeholders - that is - those who will be bearing the consequences of the decisions made.

These answers enable us to claim that several specific outcomes have been produced. These outcomes include community and capacity-building, and the ontological and educational functionality that it brings to groups of stakeholders or users who gain from being part of the modeling processes (Voinov and Bousquet, 2010; Krueger et al., 2012). Specifically, this study has favored a closer relationship between the University of Guanajuato and the Silao-Romita COTAS council. Following this work, a partnership between the two organizations has been launched for cooperation and research activities in relation to water issues. Recently, this agreement has produced a number of projects involving researchers and students of the university that are focused on solving the key problems in the aquifer. Secondly, important links have been established with the CEAG, and this has resulted in the University of Guanajuato gaining crucial support (particularly in terms of access to data, previous studies, and information) while consultations and site visits have been favored. Moreover, research groups from the university have been included within aquifer related institutions. The synergy among stakeholders has meant that various projects funded by Guanajuato University are now focusing on pollution, efficient use of water in agriculture and cities, as well as the use of alternative sources such as rainwater. The University of Guanajuato is investing in the development of these projects, and in the Guanajuato Campus the theme of water has been established as a priority in the allocation of development funds. Despite 
the fact that the problems have not yet been solved, the project has prompted local institutions to make important strides towards an eventual solution or, at least, an improvement of the conditions of the aquifer.

\section{Acknowledgments}

This work has been supported by project IDAWAS, DPI2009-11591 of the Spanish Ministry of Science and Innovation; with supplementary support from ACOMP/2011/188 of the education department of the Generalitat Valenciana. The first author wishes to thank CONACYT for the I0007-2011-01 scholarship program. The use of English in this paper was revised by John Rawlins.

\section{References}

Awasthi, A., Chauhan, S.S., 2011. Using AHP and Dempster-Shafer theory for evaluating sustainable transport solutions. Env. Model. Softw. 26(6), 787-796.

Aznar, J., Guijarro, F., 2008. Nuevos métodos de valoración. Modelos multicriterio. Universidad Politécnica de Valencia. España.

Beierle, T. C., 2002. The quality of stakeholder-based decisions. Risk Anal. 22, 739-749.

Benítez, J., Delgado-Galván, X., Izquierdo, J., Pérez-García, R., 2011a. Achieving matrix consistency in AHP through linearization. Appl. Math. Model. 35, 4449-4457.

Benítez, J., Delgado-Galván, X., Gutiérrez, J. A., Izquierdo, J., 2011b. Balancing Consistency and Expert Judgment in AHP, Math. Comp. Model., 54, 1785-1790.

Benítez, J., Izquierdo, J., Pérez-García, R., Ramos-Martínez, E., 2013a. A simple formula to find the closest consistent matrix to a reciprocal matrix. App. Math. Model., under review.

Benítez, J., Delgado-Galván, X., Izquierdo, J., Pérez-García, R., 2013b. Consistent completion of incomplete judgments in decision making using AHP. Appl. Math. Comp., under review.

Bennett, N. D., Croke, B. F. W., Guariso, G., Guillaume, J. H. A., Hamilton, S. H., Jakeman, A. J., Marsili-Libelli, S., Newham L. T. H., Norton J. P., Perrin Ch., Pierce S. A., Robson B., Seppelt, R., Voinov, A. A., Fath B. D., Andreassian, V. 2013. Characterising performance of environmental models. Env. Model. Softw. 40, 1-20.

Bojórquez-Tapia, L. A., de la Cueva, H., Díaz, S., Melgarejo, D., Alcantar, G., Solares, M.J., Grobet, G., Cruz-Bello, G., 2004. Environmental conflicts and nature reserves: redesigning Sierra San Pedro Martir National Park, Mexico. Biol. Conserv. 117, 111-126.

Bottero, M., Comino, E., Riggio, V., 2011. Application of the Analytic Hierarchy Process and the Analytic Network Process for the assessment of different wastewater treatment systems. Env. Model. Softw. 26(10), 1211-1224.

Burton, P., Goodlad, R., Croft, J., Abbott, J., Hastings, A., Macdonald, G., Slater, T., 2004. What Works in Community Involvement in Area-Based Initiatives? A Systematic Review of the Literature. University of Bristol and University of Glasgow, London.

Castelletti, A., Soncini-Sessa, R., 2006. A procedural approach to strengthening integration and participation in water resource planning. Env. Model. Softw. 21, 1455-1470.

CCLCH, 2010. Consejo de Cuenca Lerma-Chapala. Reglas Generales de Integración, Organización y Funcionamiento del Consejo de Cuenca Lerma Chapala. November, 2010. http://www.lermachapala.org/

CEAG, 2012. Manejo integral y sustentable de acuíferos. Academic meeting UG-CEAG, April $19^{\text {th }}, 2012$. Guanajuato, México. 
CEASG, 1998. Estudio hidrogeológico y modelo matemático del acuífero Silao-Romita. México. (Hydrogeological study and mathematical model of the aquifer of the valley of Silao-Romita, Gto), performed by Lesser y Asociados S.A.

Ceccato, L., Giannini, V., Giupponi, C., 2010. A participatory Approach to Assess the Effectiveness of Responses to Cope with Flood Risk, Nota di lavoro, Fondazione Eni Enrico Mattei, http://hdl.handle.net/10419/43503.

CONAGUA. 2008. Programa Nacional Hídrico 2007-2012. México.

CONAGUA. 2011. Estadísticas del agua en México. México.

Delden, H., Seppelt, R., White, R., Jakeman, A.J. 2011. A methodology for the design and development of integrated models for policy support. Env. Model. Softw. 26(3), 266-279.

Delgado-Galván, X., Izquierdo, J., Benítez, J., Pérez-García, R., Martínez, J., 2012a. Action Prioritization to Address the Silao-Romita Aquifer Problem through the Analytic Hierarchy Method. R. Seppelt, A.A. Voinov, S. Lange, D. Bankamp (Eds.): Managing Resources of a Limited Planet: Pathways and Visions under Uncertainty. Proc. of the iEMSs Sixth Biennial Meeting. Leipzig (Germany), 1544-1551.

Delgado-Galván, X., Izquierdo, J., Martínez, J., Martínez, J., Morales, R., Martínez, A., 2012b. Análisis de la problemática del acuífero Silao-Romita. Proc. of XXV Congreso Latinoamericano de Hidráulica, San José, Costa Rica.

Demeritt, D., Dyer, S., Millington, J. D. A., 2009. PEST or Panacea? Science, Democracy, and the Promise of Public Participation. Environment, Politics and Development Working Paper Series Department of Geography, King's College London, Paper \#10.

Dong, Y., Xu, Y., Li, H., Dai, M., 2008. A comparative study of the numerical scales and the prioritization methods in AHP, European Journal of Operational Research 186, 229-242.

European Commission, 2000. Directive 2000/60/EC of the European Parliament and of the Council establishing a framework for community action in the field of water policy. Official Journal OJ L 327, European Commission, Brussels, Belgium.

Figueira, J., Greco, S., Ehrgorr, M., 2005. Multiple criteria decision analysis: state of the art surveys, New York: Springer.

Fischer, F., 2000. Citizens, experts and the environment. The Politics of Local Knowledge. Duke University Press, London.

Forman, E., Peniwati, K., 1998. Aggregating Individual Judgements and Priorities with the Analytic Hierarchy Process. Eur. J. of Oper. Res. 108, 165-169.

Foster S., Garduño, H., Kemper, K., 2004. México - los COTAS: Avances en la gestión participativa del agua subterránea en Guanajuato". Colección de casos esquemáticos, caso 10. Banco Mundial-programa asociado de la GWP.

Foster, S., Garduño, H., 2009. Gestión apropiada. El recurso hídrico subterráneo en América Latina. Lecciones de experiencias internacionales. Revista Aqua-LAC, Año 1 No.1.

Gao, L, Hailu, A., 2012. Ranking management strategies with complex outcomes: An AHP-fuzzy evaluation of recreational fishing using an integrated agent-based model of a coral reef ecosystem, Env. Model. Softw. 31, 3-18.

Giupponi, C., 2007. Decision Support Systems for implementing the European Water Framework Directive: The MULINO approach, Env. Model. Softw. 22(2), 248-258.

Giupponi, C., Sgobbi, A., Mysiak, J., Camera, R., Fassio, A., 2008. NetSyMoD - An integrated Approach for Water Resources Management. In: Meir, P., Coenen, M., Lombardo, C., Robba, M. and Sacile, R. (ed.), Integrated Water management, 69-93, Netherlands: Springer. 
Greco, S., Matarazzo B., Slowinski, R., 2005. Decision Rule Approach. In: Figueira, J., Greco, S., Ehrgott, M. (eds.), Multiple Criteria Decision Analysis: State of the Art Surveys, 507-562. Springer Verlag, Boston, Dordrecht, London.

Guitouni, A., Martel, J.M., 1998. Tentative Guidelines to Help Choosing the Appropriate MCDA Method. Eur. J. of Oper. Res. 109, 501-521.

Ishizaka, A., Labib, A., 2011. Review of the main developments in the analytic hierarchy process, Expert Syst. Appl. 38, 14336-14345.

Kablan, M. M., 2004. Decision support for energy conservation promotion: an analytic hierarchy process approach. Energy Policy 32, 1151-1158.

Kelly (Lechter), R. A., Jakeman, A. J., Barreteau, O., Borsuk, M. E., El Sawah, S., Hamilton, S. H., Henriksen, H. J., Kuikka, S, Maier, H. T., Rizzoli, A. E., Delden, H., Voinov, A. A., 2013. Selecting among five common modelling approaches for integrated environmental assessment and management. . Env. Model. Softw. 47, 159-181.

Krueger, T., Page, T., Hubacek, K., Smith, L., Hiscock, K., 2012. The role of expert opinion in environmental modelling. Env. Model. Softw. 36, 4-18.

Letcher, R., Giupponi, C., 2004. Policies and tools for sustainable water management in the European union. Env. Model. Softw. 20, 93-98.

Lippe, M., Thai Minh, T., Neef, A., Hilger, T., Hoffmann, V., Lam, N. T., Cadisch, G. 2011. Building on qualitative datasets and participatory processes to simulate land use change in a mountain watershed of Northwest Vietnam. Env. Model. Softw. 26(12), 1454-1466.

Maarten, S., Selvin, A.M., 1996. Towards a Framework for Collaborative Modeling and Simulation. Proceedings of the 1996 ACM Conference on Computer Supported Cooperative Work (CSCW'96). Boston, Massachusetts, USA. ACM, New York.

Macharis, C., Springael, J., De Brucker, K., Verbeke, A., 2004. PROMETHEE and AHP: The design of operational synergies in multicriteria analysis. Strengthening PROMETHEE with ideas of AHP. Eur. J. of Oper. Res. 153, 307-317.

Mysiak, J., Giupponi, C., Rosato, P., 2005. Towards the development of a decision support system for water resources management. Env. Model. Softw. 20(2), 203-214.

Oliver, D. M., Fish, R. D., Winter, M., Hodgson, C. J., Heathwaite, A. L., Chadwick, D. R. 2012. Valuing local knowledge as a source of expert data: Farmer engagement and the design of decision support systems. Envi. Model. Softw. 36, 76-85.

Oliver, P., 2002. Natural Resource and Environmental Management Partnerships: Panacea, Placebo or Palliative? Coast to Coast 2002, 333-336.

Pohekar S. D., Ramachandran M., 2004, Application of multi-criteria decision making to sustainable energy planning - A review. Renew. Sustain. Energy Rev. 8, 365-381.

Reed, M., 2008. Stakeholder participation for environmental management: A literature review. Biol. Conserv. 141, 2417-2431.

Reed, M.S., Dougill, A.J., Baker, T., 2008. Participatory indicator development: what can ecologists and local communities learn from each other? Ecol. Appl. 18(5): 1253-69.

Richards, C., Blackstock, K. L., Carter, C. E., 2004. Practical Approaches to Participation SERG Policy Brief No. 1. Macauley Land Use Research Institute, Aberdeen.

Rittgen, P., 2007. Negotiating Models. In: J. Krogstie, A. L. Opdahl, and G. Sindre, editors, CAiSE 2007, LNCS vol. 4495, Springer, pp. 561-573.

Rouwette, E., Vennix J., Van Mullekom, T., 2002. Group Model Building Effectiveness. A Review of Assessment Studies. Syst. Dyn. Rev. 18(1), 5-45. 
Saaty, T.L., 1977 A scaling method for priorities in hierarchical structures. J. of Math. Psychol. 15, 234-281.

Saaty, T.L., 1980. The Analytic Hierarchy Process. NewYork: McGraw-Hill.

Saaty, T.L., 2001. The Analytic Network Process. RWS Pub., Pittsburgh.

Saaty, T.L., 2003. Decision-making with the AHP: Why is the principal eigenvector necessary. Eur. J. of Oper. Res. 145, 85-91.

Saaty, T. L., Peniwati, K., 2007. Group Decision Making: Drawing Out and Reconciling Differences. RWS Publications, Pittsburgh, PA.

Saaty, T.L., 2008a. Relative Measurement and Its Generalization in Decision Making. Why Pairwise Comparisons are Central in Mathematics for the Measurement of Intangible Factors|. The Analytic Hierarchy/Network Process, Revista de la Real Academia de Ciencias Serie A: Matemáticas 102 (2) 251-318.

Saaty, T.L., 2008b. Decision Making with the Analytic Hierarchy Process. Int. J. Serv. Sci. 1(1), 83-98.

Sànchez-Marrè, M., Gibert, K., Sojda, R.S., Steyer, J.P., Struss, P., Rodríguez-Roda, I., Comas, J., Brilhante, V., Roehl, E. A., 2008. Intelligent Environmental Decision Support Systems. Environmental Modelling, Software and Decision Support, Elsevier B.V., Ch. 8.

Sandoval, R., 2004. A participatory approach to integrated aquifer management: The case of Guanajuato State, Mexico, Hydrogeol. J. 12, 6-13.

Sgobbi, A., Giupponi, C., 2007. Models and decision support systems for participatory decision making in integrated water resource management. In: CIHEAM-IAMB, Water saving in Mediterranean agriculture and future research needs, 259-271, Options Méditerranéens: Série B. Etudes et Recherches 56. Bari, Italy.

Soncini-Sessa, R., Cellina, F., Pianosi, F., Weber, E., 2007. Integrated and Participatory Water Resources Management. Practice. Elsevier, Amsterdam, The Netherlands.

Stewart, G.W., 2001. Matrix Algorithms, vol. II, SIAM.

Stringer, L.C., Reed, M.S., Dougill, A.J., Rokitzki, M., Seely, M., 2007. Enhancing participation in the implementation of the United Nations Convention to Combat Desertification. Nat. Resour. Forum 31, 198-211.

Vargas, L.G., 1990. An overview of the analytic hierarchy process and its applications. Eur. J. of Oper. Res. 48(11), 2-8.

Vedwan, N., Ahmad, S., Miralles-Wilhelm, F., Broad, K., Letson, D., Podesta, G., 2008. Institutional Evolution in Lake Okeechobee Management in Florida: Characteristics, Impacts, and Limitations. Water Resources Management 22, 699-718.

Voinov, A., Bousquet, F., 2010. Modelling with stakeholders. Env. Model. Softw. 25(11), 12681281.

Wester P., Hoogesteger J., Vincent L., 2009. Local IWRM organizations for groundwater regulation: the experiences of the Aquifer Management Councils (COTAS) in Guanajuato, Mexico". Natural Resources Forum 33(1), 29-38.

Wester, P., Sandoval Minero, R., Hoogesteger, J., 2011. Assessment of the development of aquifer management councils (COTAS) for sustainable groundwater management in Guanajuato, Mexico, Hydrogeology Journal 19: 889-899.

Younge, A., Fowkes, S., 2003. The cape action plan for the environment: overview of an ecoregional planning process. Biol. Conserv. 112, 15-28. 